\title{
Desired Machines: Cinema and the World in Its Own Image
}

\section{Citation}

Canales, Jimena. 2011. Desired machines: Cinema and the world in its own image. Science in Context 24(3): 329-359.

\section{Published Version}

doi:10.1017/S0269889711000147

\section{Permanent link}

http://nrs.harvard.edu/urn-3:HUL.InstRepos:10406378

\section{Terms of Use}

This article was downloaded from Harvard University's DASH repository, and is made available under the terms and conditions applicable to Other Posted Material, as set forth at http:// nrs.harvard.edu/urn-3:HUL.InstRepos:dash.current.terms-of-use\#LAA

\section{Share Your Story}

The Harvard community has made this article openly available.

Please share how this access benefits you. Submit a story.

\section{Accessibility}




\section{Desired Machines: Cinema and the World in Its Own Image}

Jimena Canales

Harvard University

\section{Argument}

In 1895 when the Lumière brothers unveiled their cinematographic camera, many scientists were elated. Scientists hoped that the machine would fulfill a desire that had driven research for nearly half a century: that of capturing the world in its own image. But their elation was surprisingly short-lived, and many researchers quickly distanced themselves from the new medium. The cinematographic camera was soon split into two machines, one for recording and one for projecting, enabling it to further escape from the laboratory. The philosopher Henri Bergson joined scientists, such as Etienne-Jules Marey, who found problems with the new cinematographic order. Those who had worked to make the dream come true found that their efforts had been subverted. This essay focuses on the desire to build a cinematographic camera, with the purpose of elucidating how dreams and reality mix in the development of science and technology. It is about desired machines and their often unexpected results. The interplay between what "is" (the technical), what "ought" (the ethical), and what "could" be (the fantastical) drives scientific research.

\section{Introduction}

How do dreams come true? In 1760 the French author Tiphaigne de la Roche described in a fictional novel "a very subtle and very viscous substance" that when spread on a piece of cloth was able to "fix" the "rays of light" as they "reflected from different bodies, making images and painting these bodies on all polished surfaces." Years later, with the invention of photography, it seemed like de la Roche's imagined technology had become real. His description appeared like an eerie prediction of photography (Tiphaigne de la Roche 1760).

After the announcement of the daguerreotype in 1839, a number of scientists started having even more ambitious dreams. They started desiring a different kind of photographic technology: a machine for capturing and displaying movement. In 1895, when the Lumière brothers unveiled their cinematographic camera, many believed this dream had been finally fulfilled. But others, including the physiologist Etienne-Jules Marey, who had deeply desired cinematographic machines, felt that scientists did not get exactly what they wanted. 
In the eighteenth century, de la Roche also described a complex array of mirrors that could be arranged in such a way that a person could see images from afar. The mirror arrangement would enable someone to see moving reality, while the "subtle and viscous substance," would allow for "fixing" it; de la Roche did not describe a technology that would simultaneously portray movement and fix it - perhaps believing that fixing movement was ultimately paradoxical and thus impossible - even for a fictional account. How and when, then, did the "facticity of the fictive" change with respect to imagined technologies (Koselleck 2004)? How did this transformation affect research into cinematographic machines?

By the late 1870s, the dream to record movement photographically had become a veritable race. In 1895, although cinematographic spectacles were still "tiring to watch" since "the reproduced movements were jerky and accompanied by a regular fluttering which was extraordinarily disagreeable for the eye," an essential victory had taken place (Vitoux 1896). According to most viewers, the cinematographic machine was successful at producing both photographic synthesis and analysis. But the desire of early researchers to build cinematographic cameras culminated with an unexpected finale.

What I offer to our understanding of this period is not another history of cinematography, but a history of cinematographic desires. Attention to desire permits us to explore the complex relation between discourse and things, dreams and reality, without having to focus exclusively on one or the other (Deleuze and Guattari 1972; Kittler 1990). The differences between what "is" (the technical), what "ought" (the ethical), and what "could" be (the fantastical) led scientific research into new, unexpected directions. We must remember, with the philosopher Gilbert Simondon, that the "technical reality" of objects is only one aspect of a denser set of meanings (Simondon 1958; Thibault 2010). To the "technical reality" of cinematography, we will add the components of desire and anticipation - of finding a camera to capture the world in its own image.

\section{Picturing movement}

Since ancient times, a number of different pictorial techniques for depicting the unfolding of time in visual terms had been widely employed. Most prominently, these included sequential images, blurred images (primarily of wheels and disks), slightly superimposed or side-by-side figures (often in single canvas or sheet), symbols of time or instantaneity (skulls, clocks, bubbles, and lightning) and bodily poses and severed body parts associated with direction and sequence (such as pointing, poking, pulling and jumping). Scientists employed all of these techniques.

During the Counter-Reformation the use of left to right sequential images was increasingly employed for political, pedagogical, and religious aims: viewers throughout the Holy Roman Empire were exposed to the sequential images of the twelve Stations 
of the Cross as the favored technique for depicting the story of the Passion of Christ across time (Kittler 2010). By 1610 Galileo could assume that a simple depiction of sequences involving a diagrammatic circle and asterisks on either side of it would be "read" as a depiction of movement (of Jupiter's satellites around the planet). In the heated debates about the nature of sunspots that followed his Sidereus Nuncius, Galileo (fig. 1a) and his rival Christoph Scheiner (fig. 1b) once again presented their evidence as a series of sequential images (Biagioli 2006).

Soon the convention used by them was employed to depict biological and physiological phenomena. In 1621 Fabricius of Aquapendente depicted the formation of a chick from an egg using a one-per-day thirteen day-long series of sequential images. The use of sequential images increased with the development of magic lantern technologies. But sequential images were not the only format employed to depict movement. William Harvey in 1628 employed both sequences and poking fingers to illustrate the circulation of blood through the veins. In 1680 Giovanni Borelli author of De motu animalium still opted for severed hands pulling strings and suggestive, action poses. The mathematician Johannes Bernoulli, who was a student of Borelli, opted for hands pulling strings in De motu musculorum, in a manner that would characterize many treatises of mechanics during the period.

In the eighteenth century, the philosopher and critic Gotthold Lessing tried to distinguish the "arts of time" such as music and poetry from the "arts of space" that included painting. But the boundary he attempted to draw was frequently transgressed as both artists and scientists continued to use pictorial and visual technologies for depicting movement. Famously, by the end of the century, the physicist and musician Ernst Chladni showed that sand on drums and membranes settled in definite patterns according to different vibrations, drawing clear connections between auditory phenomena that took place in time and static visual forms. In 1836, the Weber brothers (Ernst Heinrich Weber and Wilhelm Eduard Weber) chose slightly superimposed sideby-side drawings in their study of human locomotion. By the middle of the century, the mathematician Jules Antoine Lissajous bounced a beam of light off a mirror attached to a vibrating tuning fork creating the famous figures that carry his name. Later in the century, a number of scientists turned to the graphic method - of which Marey was one of its main proponents in France.

Marey used various previously-employed techniques for depicting movement, including in his work suggestive poses, slightly superimposed, side-by-side, sequential images, continuous lines, and pulling hands. He also improved on new ones, such as those involving traces on a roll of blackened paper moved by clockwork mechanisms.

Like many of his generation, he dreamt of new ways of depicting movement photographically. The last chapter of his famous book Le Mouvement, which appeared the year before the Lumière brothers presented their camera, was dedicated entirely to the problem of producing the synthesis of sequential, photographic images. Marey, by then, was hardly alone in his desire to build these technologies. He faced competition on many fronts, including in-house with his assistant Georges Demenÿ. But in these 


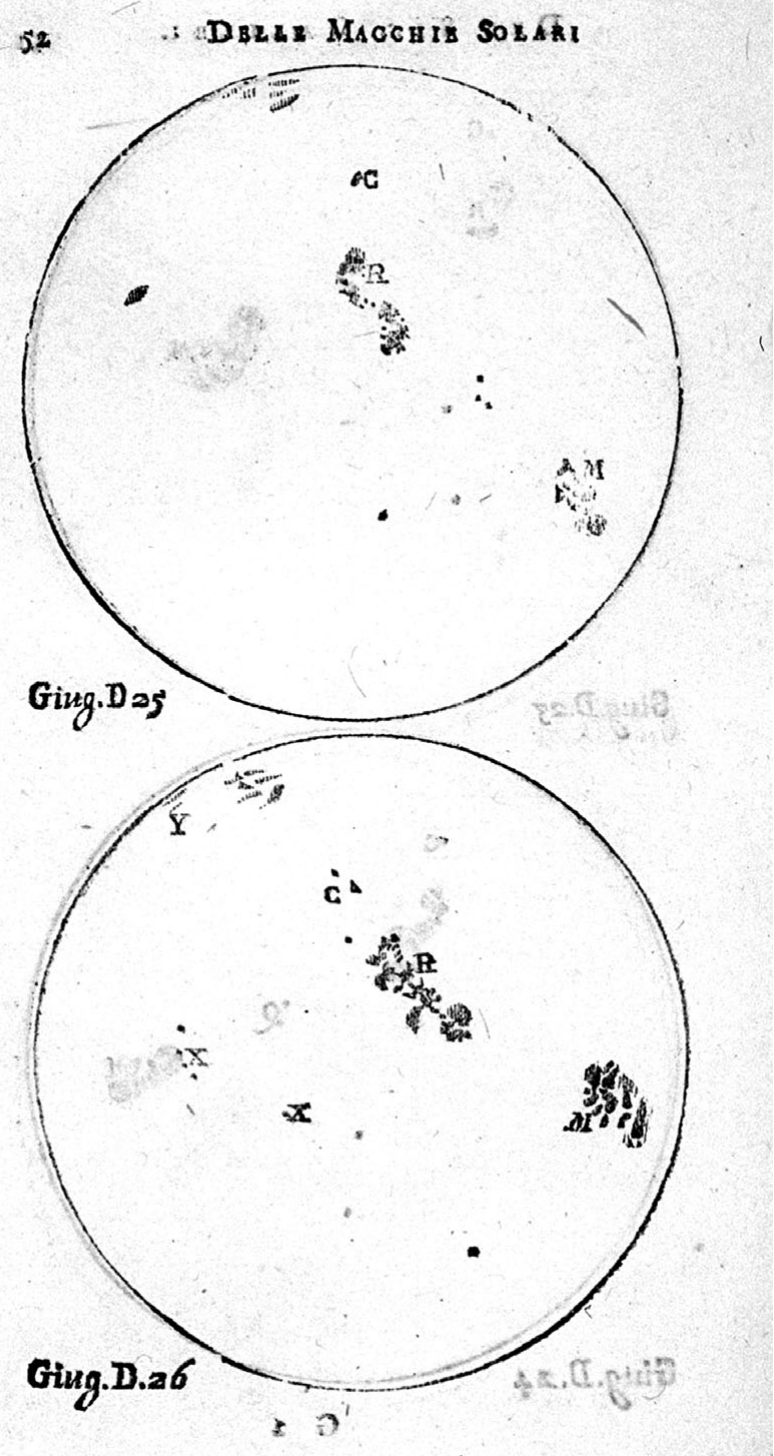

Fig. 1a. Galileo's drawings of sunspots from Istoria e dimostrazioni intorno alle macchie Solari e loro accidenti Rome (1613).

pages, he described technologies which differed in essential ways from the ones that Lumière and others would later employ and that we have come to associate with cinema. 


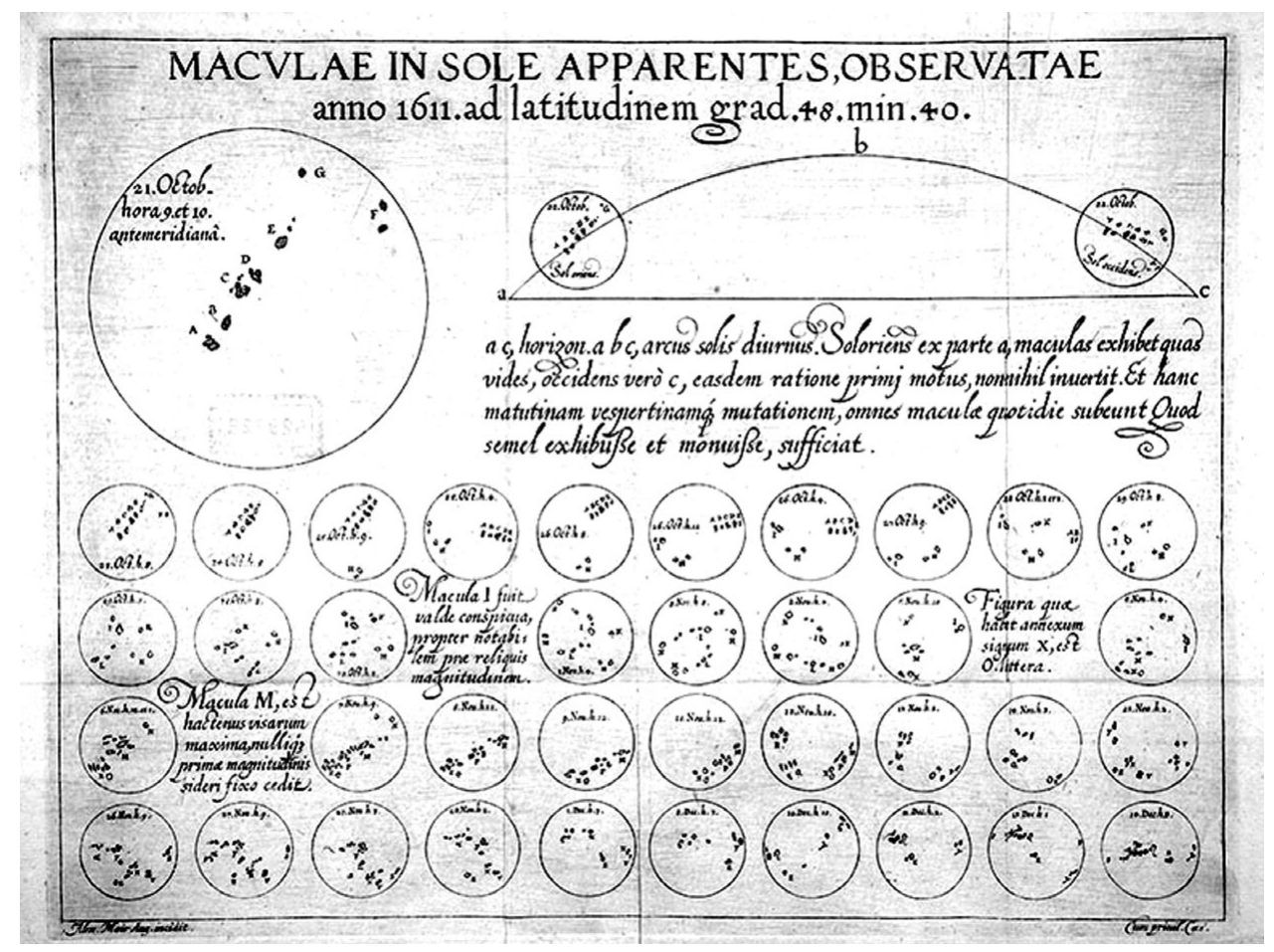

Fig. 1b. Scheiner's drawings of sunspots from Tres epistolae de maculis Solaribus (1612).

\section{Early dreams}

During the very productive years of early cinematographic research, many authors described and even patented technologies that increased the range of vision beyond what the telescope could offer (Andriopoulos 2005). Some of these devices were similar to those that de la Roche had described. But while the work of de la Roche described two separate technologies, one of fixing and the other for seeing from afar, increasingly these two merged into the same concept.

New research on the visual patterns produced by infinitely small vibrations led some scientists to argue that all moving reality left a record somewhere, and that this record was legible. Thus in 1837 Charles Babbage explained in his famous Bridgewater Treatise that "the air itself is one vast library, on whose pages are forever written all that man has ever said or woman whispered," in a chapter tellingly titled "On the permanent Impression of our Words and Actions on the Globe we inhabit." Early research on vibrations pioneered by Chladni and followed by many others would culminate with "wave physics," of which Hermann von Helmholtz and James Clerk Maxwell are the main representatives. Their research, bearing simultaneously on acoustics and optics, 
no longer fit with the eighteenth-century divisions advanced by Lessing that associated time with sound and space with painting.

Since ancient times, many different models described the way in which time was harnessed to space. For his discussions on time, Aristotle turned to common examples for understanding space. Parmenides, in turn, was widely read as having a view of the universe where time and space constituted a four-dimensional unchanging block, which some later described as cinematographic (Lee 1936; Kirk and Raven 1957). Einstein, in considering time as a fourth-dimension, was accused of providing a view of the universe which was both Parmenidian and cinematographic (Popper and Bartley 1982). In Einstein's theories, argued the philosopher Henri Bergson, the world "seemed like a screen upon which the cinematography of the universe would be run off' (Bergson [1922] 1972).

Wave physics, together with the realization that lightwaves took time to be transmitted, added a new dimension to preexisting models that related time and space, providing new ways of conceiving the universe as unfolding cinematographically (avant la lettre). In the context of this research, some of the first anticipations of cinematographic technologies appeared.

A dreamt-of technology described in 1846 permitted a viewer to see all of the world's past history, albeit as it unfolded "in reverse." Based on the delay due to the speed of light's finite velocity, which, although insignificant across short distances, was very noticeable across large ones, it would permit a viewer to see past eras (Felix Eberty [1846] 1882; Clausberg 2008). After Ole Rømer revealed in 1675 (through observations of Jupiter's satellites) that light took time to be transmitted, the educated public soon learned that the image of the stars on the heavens were images of the past, arriving at our retinas only after being delayed by light's finite speed. An observer situated far from Earth would only be able to see the planet after its image was conveyed through lightwaves, getting access to it after considerable delay. By moving to successive faraway distances from the Earth, the development of world history could be seen as images that succeeded each other at different rates. One popular science writer, who was read by Einstein in his youth, explained the possible repercussions of speed-of-light delays if an observer placed himself at very distant stars (Einstein [1949] 1991):

In one point in space, the light of the scenes of the French Revolution is just coming into view. And even farther away, the invasion of the barbarians has just become the order of the day, Alexander the Great is still conquering the World. ... And even farther away in space, the representation of Earth's past by way of light will just be advancing into the future, historical events that have long been dead for us will just be coming to life. (Bernstein 1873-1874)

An observer who could move rapidly in order to alter the time taken by world events to reach him would "comprehend with his eye the whirling procession of these 
consecutive images." Placed at a $12^{\text {th }}$ magnitude distant star, he "would see the earth at this moment as it existed at the time of Abraham." By jumping from one distant star to the next, "before the eye of this observer the entire history of the world, from the time of Abraham to the present day, passes by in the space of an hour." By moving at a fast velocity, "he will be able to represent to himself, as rapidly as he pleases, that moment in the world's history which he wishes to observe at leisure" (Felix Eberty [1846] 1882). Not only could history be studied using this "microscope for time," but biological processes such as the blooming of a flower or the butterfly in flight could also be analyzed (Felix Eberty [1846] 1882).

Astronomers continued to dream about the possibility of seeing the universe in a way that could lately be described as cinematographic. Camille Flammarion, the famous astronomer renowned for his ability to write to a popular audience, claimed in 1873 how "we have a series of terrestrial images imprinted in space, at corresponding distances, one after another." He speculated about the existence of a distant star with a light-sensitive surface that might act like a photographic plate. And if this star would rotate, successive images could be fixed creating an "imperishable" record "around which would be engraved the great events of the world's history." In these speculative texts, Flammarion laid down the principles of what he called a "chronotelescope," a machine for seeing past eras from a distance, or recording them, accelerating them, or slowing them down. He also thought of playing these images in reverse, using the image of the battle of Waterloo:

It was really a Waterloo, but a Waterloo of the afterlife, for the combatants were being raised from the dead. In this singular mirage, furthermore, they marched backward one against the other. ... No less singular was the fact that the longer they fought, the more the number of combatants increased; each gap made in the serried ranks by the cannon was immediately filled up by a group of resuscitated dead. (Flammarion 1873)

In discussions about the laws of thermodynamics in 1874 the famous physicist William Thomson also described exceptions to the law of entropy as a sequence of reversible images:

The bursting bubble of foam at the foot of a waterfall would reunite and descend into the water. ... Boulders would recover from the mud the materials required to build them into their previous jagged forms, and would become reunited to the mountain peat from which they had formerly broken away ... living creatures would grow backwards, with conscious knowledge of the future, but no memory of the past, and would become again unborn. (Thomson 1874)

Joseph Pohle, professor of astronomy at Breslau, popularized these notions in 1885, describing the possibility of observing world history as a set of "swiftly changing tableaux vivants," which could also be displayed in reverse: "[If an observer could move 
faster than the speed of light] the history of man and Earth would be turned upside down. People would first be seen on the death bed, then the sick bed, then in the prime of life and finally as an infant in the cradle" (Pohle 1885).

\section{Making the dream come true}

In the context of these speculations, scientists started to adapt photographic technologies for the purpose of capturing moving events. The astronomer Hervé Faye had high hopes for photography, especially if combined with another technology of his interest: telegraphy. By combining photography with telegraphy, Faye surmised, moving, fleeting events could be captured in a way undreamt of before.

In 1854, longitude between London and Paris was determined for the first time using telegraphy after a submarine cable was laid across the channel (Faye 1863). Faye, who was in charge of the French operation, eloquently defended its use by promising the technology an even greater future: "It is as if a French orator spoke in Paris and London at the same time, as if the banker personally gave his order at the same time to the Paris and London Stock Exchange; when necessary, he will sign in both places at the same time, and if it be needed, you could print in London and compose in Paris, or well from Regents Park you could fire the cannons at the Invalides" (Faye 1854). Most famously, at Promontory Point Utah on May 10, 1869, a golden spike connected telegraph lines that ran east and west along railroad tracks setting off cannons "simultaneously" in San Francisco and New York in what is considered to be the first national media event in the Americas. For some of these dreams to come true, telegraphic technologies had to be combined with others, such as triggers, shutters, explosives, and cannons, and at times they needed to involve telescopic lenses and photographic cameras.

Faye advocated experimental systems that combined telegraphic and photographic technologies with the explicit goal of expanding the range of vision across space and time. In 1849 he attached a photographic apparatus to a meridian telescope and to a clock. By pressing a telegraphic key, a photographic negative was automatically exposed and, using elaborate clockwork, the time of the "spontaneous" exposure was registered: "Voilà a completely automatic observation produced under our eyes by a young apprentice who had no idea what he was doing. We could have done it with a machine" (Faye 31 October 1861). When he succeeded in photographing an eclipse, he explained how "here the nervous system of the astronomer is not in play; it is the sun itself that records its transit" (fig. 2) (Faye 1858).

Faye was particularly interested in tracking the movement of transit stars with precision, an operation essential for the determination of time and longitude. Astronomers first determined sidereal time by noting the moment when the center of the sun passed a certain point. They soon found errors in estimating the center of the sun, and learned that bisecting a point-like transit star gave more exact measurements. 


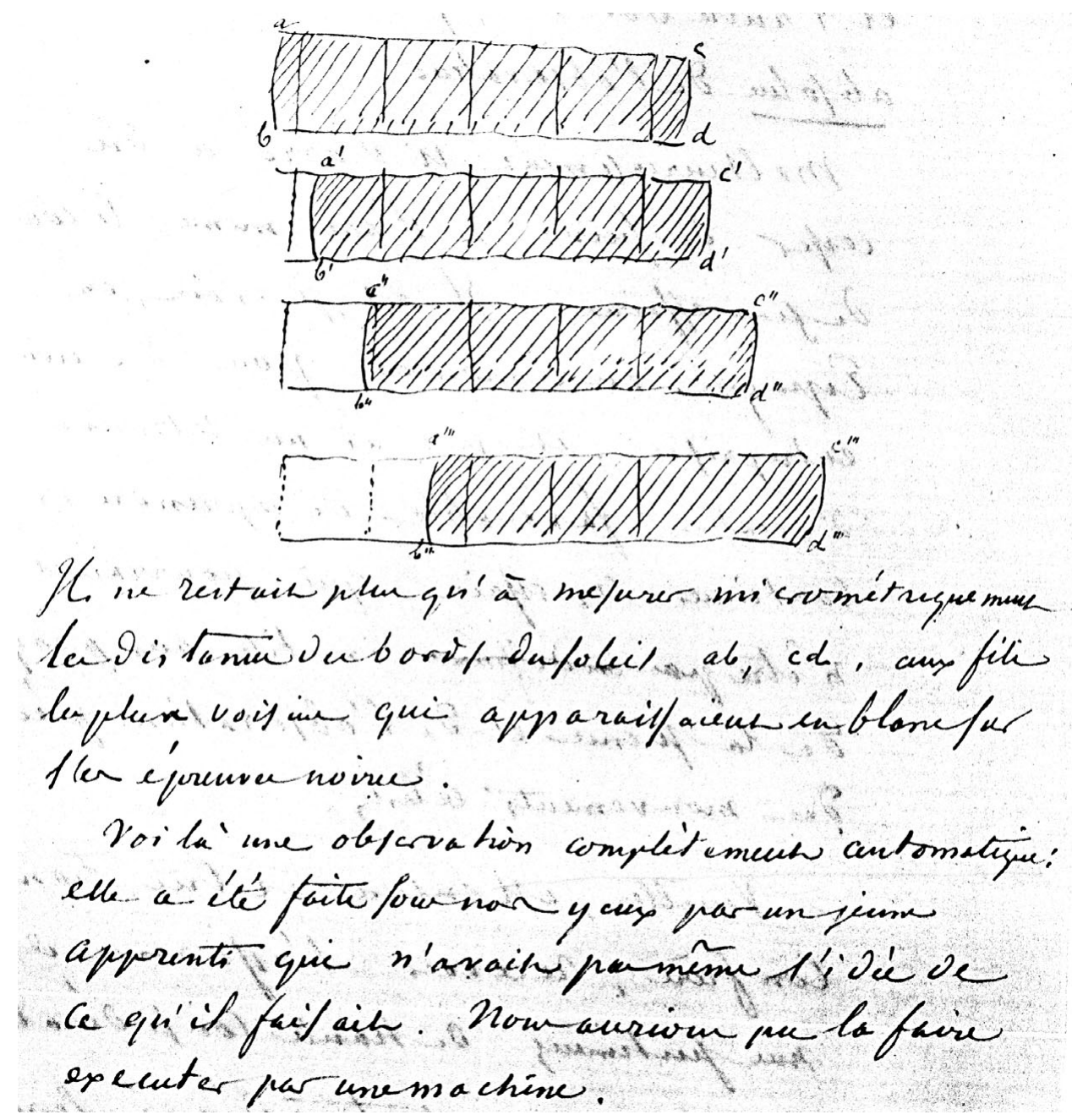

Fig. 2. Letter from Faye showing a drawing of sequential photographs of the sun's border crossing the wires of a telescope from Hervé Faye, Paris, 31 October 1861, Preußische Staatsbibliothek zu Berlin, Sammlung Darmstädter I 1846(6) Faye, 3.

Yet even when using transit stars astronomers rarely reached a level of precision beyond a tenth of a second. These differences, although small, had important consequences for precision science, especially for mapmaking and navigation. Ten accumulated mistakes of this magnitude could result in map discrepancies of nearly half a kilometer. All "determinations of absolute time" used in astronomy, Faye noted, included these errors: "One knows, since the beginning of this century, that this determination [of time] is completely illusory." According to Faye, only "relative time" could be found, and this 
one, ironically, with a much greater precision. The problem plagued not only France and its observatories, but "all places where one observes, with an admirable precision, astronomical phenomena." The scourge reached as far as Poulkova, Koenisberg, and Greenwich, sites of the most important observatories and, places where "one could not find two observers reach accord on absolute time" (Faye 1849). These errors affected not only determinations of time and longitude, but many other observations of fast and fugitive events such as eclipses, occultations, comets, sunspots, solar prominences, and flares. It was clear that all observations of fast, moving events were haunted by these errors.

To combat these errors, astronomers started employing telegraphic technologies in their observatories. Instead of estimating the place of a star between successive beats of a pendulum, observers could press a telegraphic key when a star passed a certain point and recorded this moment automatically on a strip of paper. They used this same experimental system for the determination of longitude. By comparing the difference in time when the same astronomical event was perceived in two distant places joined by a telegraphic wire, astronomers could deduce the longitudinal distance between them.

Faye's decision to adopt telegraphic technologies was driven by his desire to eliminate errors that arose from an "inherent imperfection due to the intimate nature and the individuality itself of observers" (ibid.). These errors were described in most detail in a publication titled "Sur les erreurs d'origine physiologique" (Faye 1864). In it, the astronomer remarked that scientific observations of moving events were frequently deficient because "sensations separated by a very real interval will be falsely noted as simultaneous" (Faye 12 September 1864). This deficiency was amply demonstrated in the case of vision. Since the 1830s, pre-cinematographic technologies such as phenakistiscopes and zoetropes, in which sequential images passed in front of the eyes of an observer in quick succession to furnish an illusion of movement, confirmed these deficiencies. But it was also the case with hearing and even with touch. He cited experiments where 500 vibrations per second applied to the skin were sensed as continuous.

Faye speculated how errors in perceiving moving events could be eliminated with photo-telegraphic technologies. The photographic camera component was particularly valuable because most of the errors were visual. Faye's postlapsarian observer was naturally flawed, seeing only what he wanted to see, "one only sees the things in which the observer is interested at the time of observation. The rest almost always escapes our unprepared attention" (Faye 12 September 1864). When Faye described the scientific observer he saw a fragile person, accosted by his unconscious, troubled by processes of "digestion, blood circulation or nervous fatigue" and whose "attention" was always limited. Instead of having to "determine the error of almost every observation," Faye "asked astronomers instead to eliminate the human machine, whose imperfections are revealed to us in an alarming way" (ibid.).

Problems in determining time and longitude in astronomy led him to search for technologies that used sequential photography to capture moving events. These 


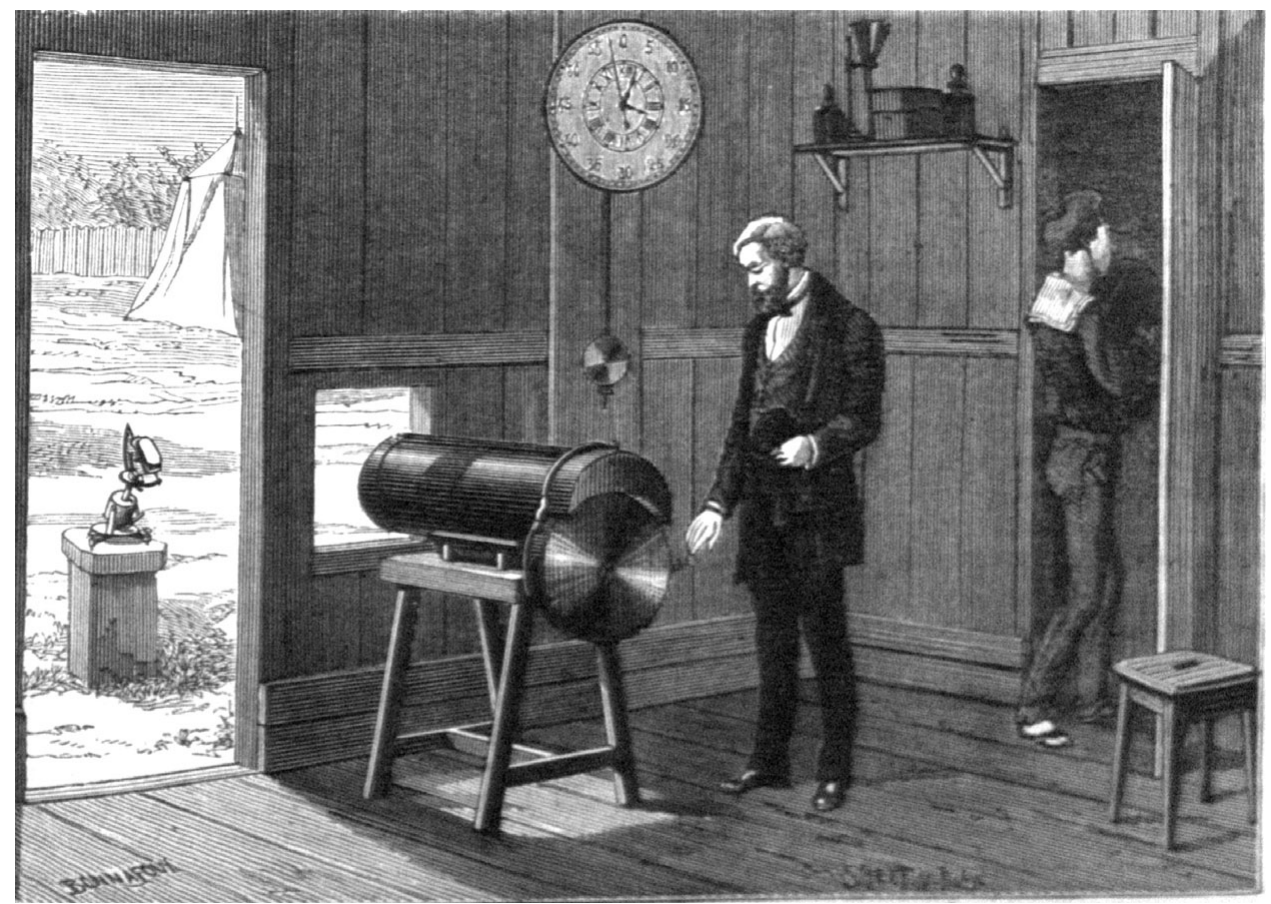

Fig. 3a. Janssen's photographic revolver from La Nature (1875), p. 357.

technological ensembles connected a camera to a clockwork mechanism via telegraphic wires. Yet despite some initial successes, technical difficulties prevented his automatic machine from succeeding. Unfazed, Faye still dreamed about using telegraphic, clockwork, and photographic technologies for eliminating "the human machine" in the near future.

\section{"The history of heavens, written by the heavens themselves"}

Faye became one of the chief supporters of the astronomer Jules Janssen, inventor of a controversial new instrument, intriguingly named the "photographic revolver" (fig. 3a). The revolver was first designed to photograph Venus's 1874 transit across the sun, an astronomical event widely considered to be the most important one of the century because of its rarity (approximately twice in a century) and its connection to a central constant used in celestial mechanics, the solar parallax. When astronomers during the late nineteenth century reviewed observations of the previous century's transit of Venus the conclusion was appalling: different people perceived the planet's movement across the sun in different ways. 


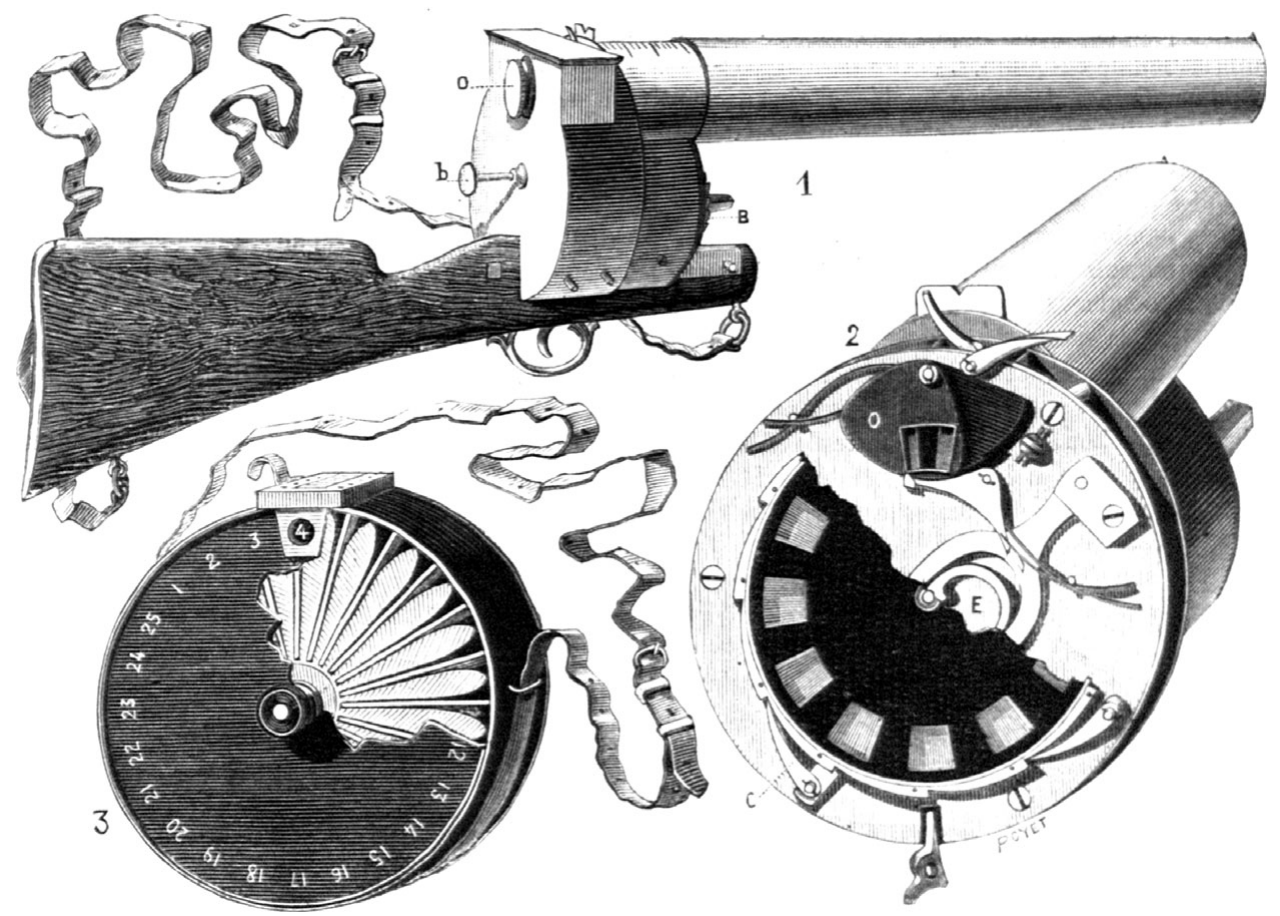

Fig. 3b. Marey's photographic gun from La Nature (1882), p. 329.

Observations of the movement of sunspots were similarly contentious during this period. The precise determination of their movement had - even centuries earlier driven scientists of the stature of Galileo to employ some of the first sequential images in the sciences. In the late nineteenth century, debate about the nature of sunspots continued, and the dream to capture their movement intensified. Some scientists believed that the dance of these dots on the surface of the sun proved that they were not sunspots at all, but rather intra-mercurial planets. Others took their motion as evidence that they were firmly part of the sun's surface (Janssen 14 October 1876; Le Verrier 14 October 1876). The inventor of the photographic revolver claimed that photographic evidence clearly demonstrated that they belonged on the sun, and that they were not merely floating above it. He gave a lecture, later republished in the popular Revue scientifique, in which he showed how different astronomers had portrayed the movement of sunspots at different times. He started with a drawing by Fabricius (1611), moved successively through drawings by Galileo, Christoph Scheiner (1626), William Herschel (1801), and John Herschel (1837). After showing the divergent drawings of his contemporaries, he concluded: "This short examination is sufficient for showing to us the disaccord that exists even amongst the best observers when observing solar phenomena. It convincingly demonstrates that the true method for observing them is 
to obtain, firstly, images drawn by the sun itself" (Janssen 14 January 1888a; Janssen 1888b). He echoed Faye, his predecessor in sequential astronomical photography, who had much earlier claimed to have sequential photographs authored by the "sun itself." With photography, Janssen (and Faye before him) sought to shift the "authorship" of the sun's images away from themselves and to the star itself, attempting in the process to solve the problems that arose when observing and portraying movement. ${ }^{1}$

In 1882 the physiologist Etienne-Jules Marey transformed Janssen's revolver into a faster "photographic gun," producing his famous images of flying birds. He portrayed his work as a continuation of Janssen's (fig. 3b). Marey, like both Faye and Janssen before him, described his imaging techniques as unmediated, direct representations, using a rhetoric that characterized much of early scientific photography (Marey 1889). "It is the sun itself that records its transit," claimed Faye (Faye 1858). Photographs were "images drawn by the sun itself," showing "the history of heavens [Ciel], written by the heavens themselves," he continued (Janssen 14 January 1888; Janssen 1883; Janssen 1888b). "The stars shall henceforth register themselves," echoed others across the Atlantic (Pang 1997).

\section{Problems realizing the dream}

One seemingly minor detail undermined these grandiose claims. When photographs were used in technologies for synthesis, such as magic lanterns, phenakistiscopes, and zoetropes, the resulting image was slightly, but significantly, deformed. Magic lanterns, phenakistiscopes, and zoetropes were, by the second half of the century, widely popular animation devices that effectively reproduced movement, but they were mostly based on drawings. By the last decade of the century, these kinds of technologies were used to project longer spectacles on large screens (figs. $4 \mathrm{a}$ and $4 \mathrm{~b}$ ). For observers at the time, the scientific worth of sequential photographs depended on the possibility of producing the illusion of synthesis with them.

Scientists wanted to produce the effects of movement with sequential photographs. "An absolute proof of [sequential images'] truthfulness" could only be established by "subjecting them to the test of the zoetrope" (Cuyer 1883). Methods of photographic synthesis were considered necessary "counter-proofs" and "cross-checks" to techniques of analysis (Banet-Rivet 1 August 1907). Synthesis was the "crosscheck used by all experimental sciences to verify the results of analysis, which is imposed in an absolute manner" (ibid.). Combining photographs with magic lanterns, phenakistiscopes, and zoetropes became a scientific imperative during the second half of the nineteenth century. It was one of the desires that drove the research of Janssen and Marey.

When Janssen first introduced his revolver, he claimed that it had solved the "inverse problem of the phenakistiscope," but the relation between chronophotographic

\footnotetext{
${ }^{1}$ For the question of scientific authorship, see Biagioli and Galison 2003.
} 


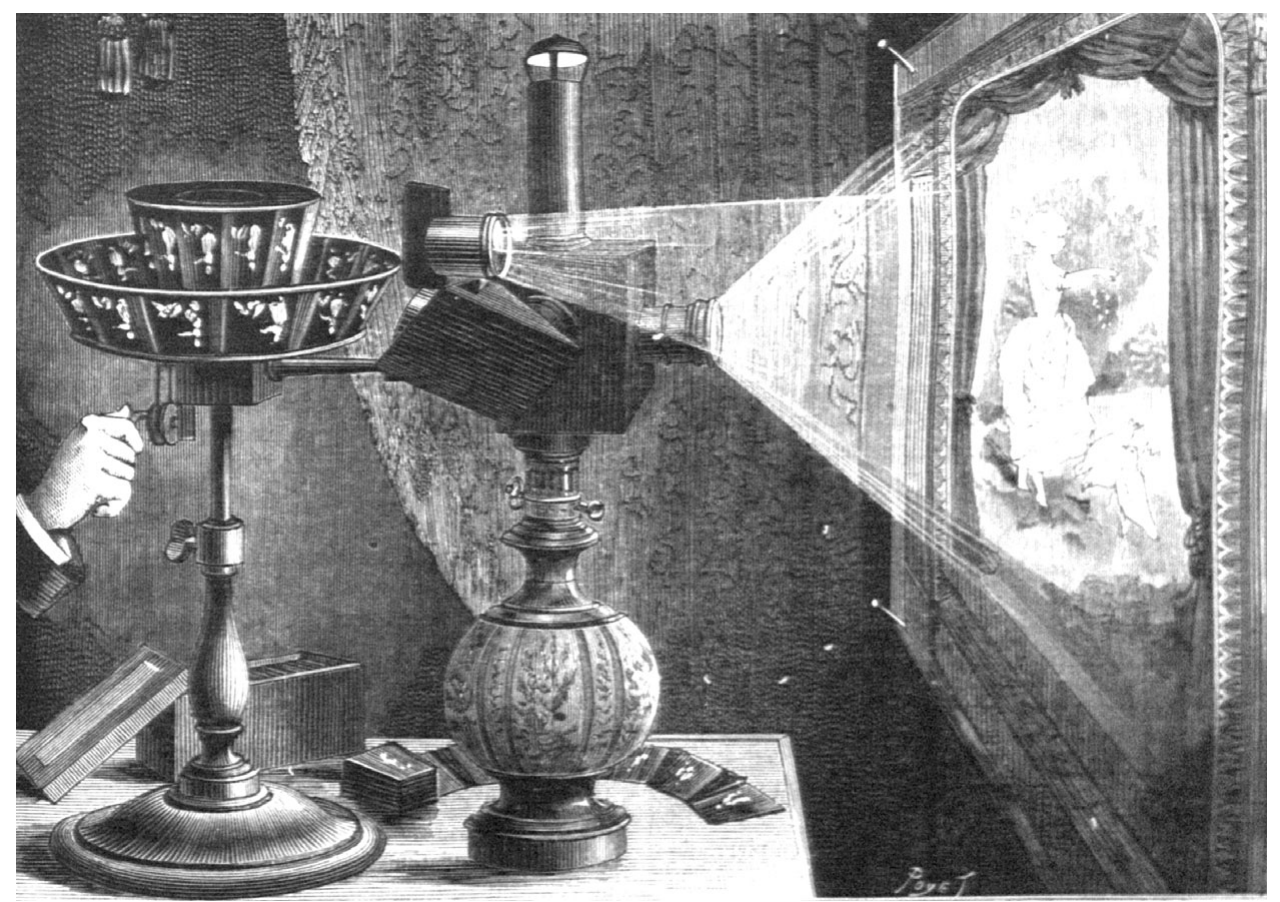

Fig. 4a. Émile Reynaud's praxinoscope La Nature (1882), p. 357.

cameras and technologies of synthesis was not clear. It would take more than two decades of intensive research to clarify their relation. Scientists took and retook photographs varying times of exposure, points of view, and the speed of their succession while they arranged and rearranged them on spinning disks, but they could not achieve the effect of synthesis in the way that was done using drawings. Janssen's transit of Venus revolver daguerreotype could not be used to recreate the event without significant modification. A few photographs of Venus's apparent contact with the sun taken with the revolver had to be selected from the many images in the original daguerreotype. They had to be rearranged and copied unto another disk in order for them to appear to move. For decades, scientists could not entirely explain why rapidly succeeding snap-shots did not merge easily into moving pictures, like sequential drawings so spectacularly did (figs. 5a, 5b, and 5c).

In Le Mouvement, Marey was clear about the problems that photographers faced. "In principle at least," photographs should work, but "in practice," they did not (Marey 1894). When used with a phenakistiscope, photographs showed images that were "slightly deformed ... and sensibly shortened." They could only employ drawings made after photographs since these could be "elongated" by hand in order to counter these deformities (ibid.). Furthermore, a few representative photographs had to be 


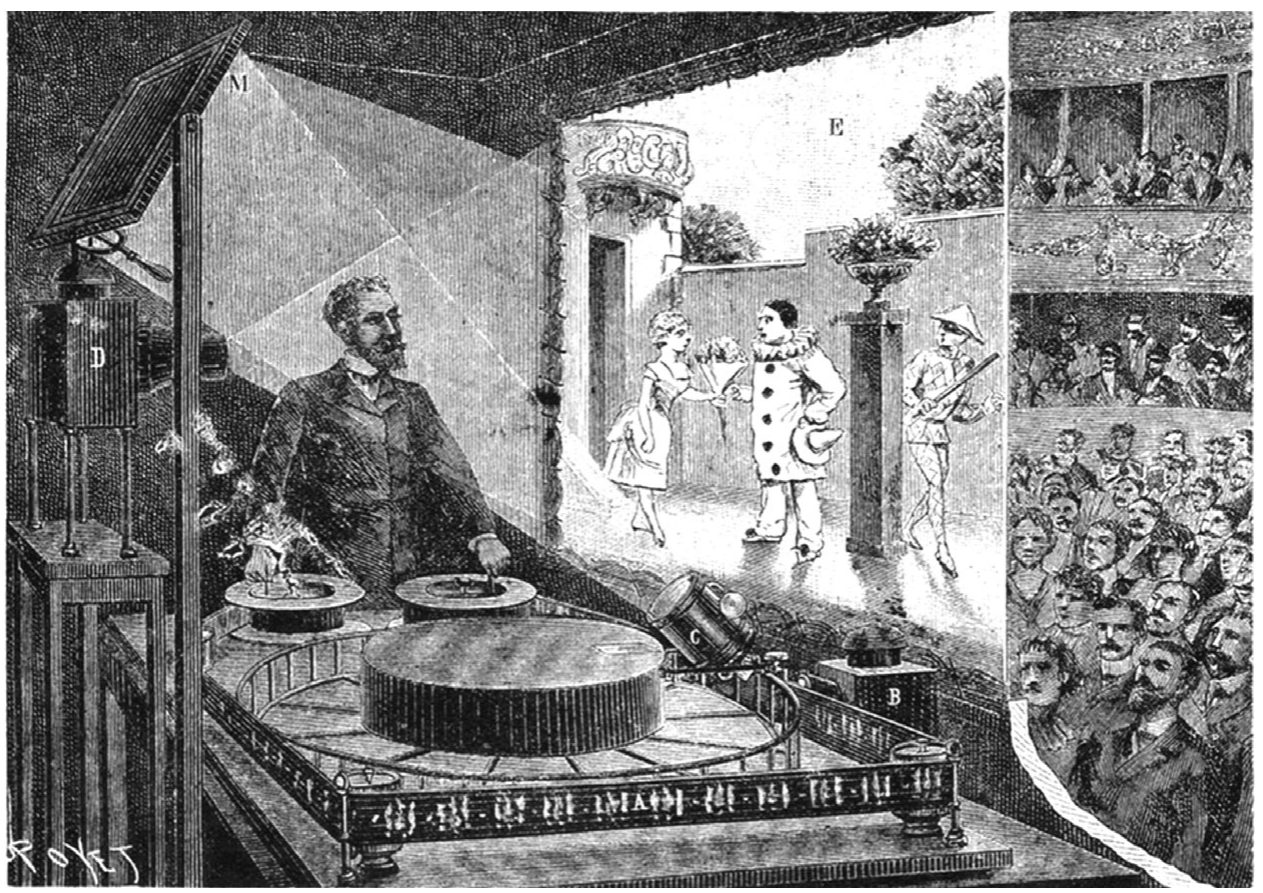

Fig. 4b. Public presentation of Emile Reynaud's Théâtre Optique from La Nature (1890), p. 128.

selected from the sequential series. A cut-and-paste operation, which he referred to as an "artificial dissociation," was necessary to render them fit for synthesis (Marey 1888).

Because of these problems in achieving synthesis, photographs were scientifically suspect, stubbornly different (and frequently deemed inferior) to direct observations or hand-drawn images. Photography's perceived inferiority in revealing movement, especially when compared to drawings, distanced it from the coveted empirical base of vision.

The photographer Eadward Muybridge, famous for capturing "the horse in motion" in 1877 (fig. 6a), also encountered problems when he tried to animate his photographs. He was extremely successful in using drawings made after photographs for the illusion of movement, but he was unable to use the photographs themselves. For Marey, this task was even more complicated since he was stricter than Muybridge in terms of how he defined analysis. Muybridge had used multiple cameras to create photographs in which "successive images are taken from different points of view" (fig. 6b). In contrast, Marey underlined "the need to take, from a fixed point of view, the series of successive images" (ibid.). He also insisted that "photographs be taken at very short and equal intervals of time" (Marey 1902). 


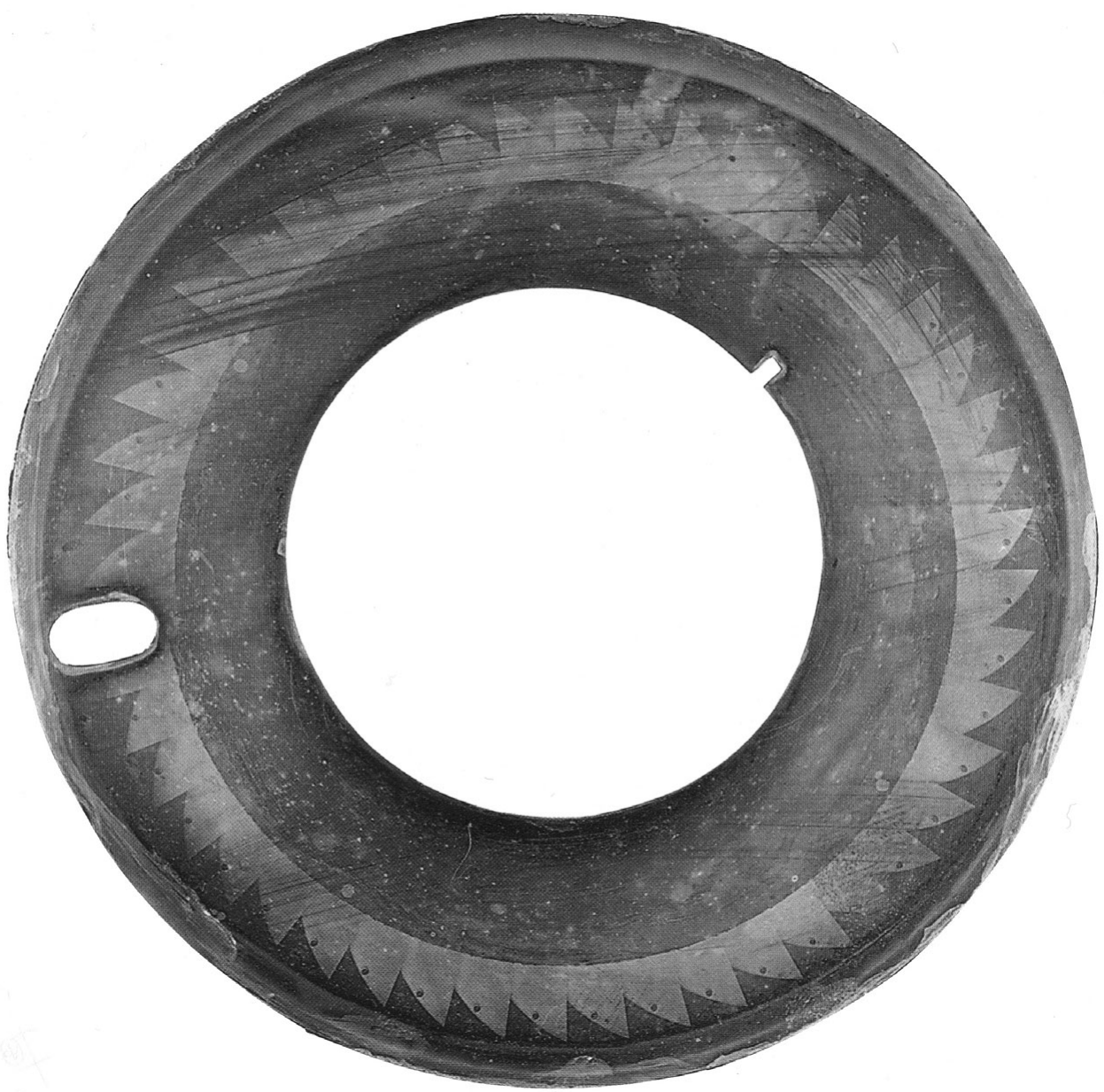

Fig. 5a. The following three images reveal how selected parts of the daguerreotype of the transit of Venus expedition taken with Janssen's photographic revolver were selected and rearranged on a spinning disk. The first image shows the complete daguerreotype of Venus's contact with the sun. From Monique Sicard, "Passage de Vénus. Le revolver photographique de Jules Janssen." Études photographiques, no. 4 (1998): 45-63.

What caused these problems and how could they be solved? Marey tried arranging painted wax sculptures of flying birds and placing them inside the wheel of a zoetrope to produce a moving three-dimensional view (1887) (fig. 7). He also continued working with drawings, producing images that "as those of Muybridge, can be examined with a zoetrope" (Marey 1888). He even attached an electric motor to power these spinning cylinders, and displayed "a zootrope moved by electricity" showing "animals in motion, as well as men, birds, horses at different gaits” (Marey 1902). But Marey was never 


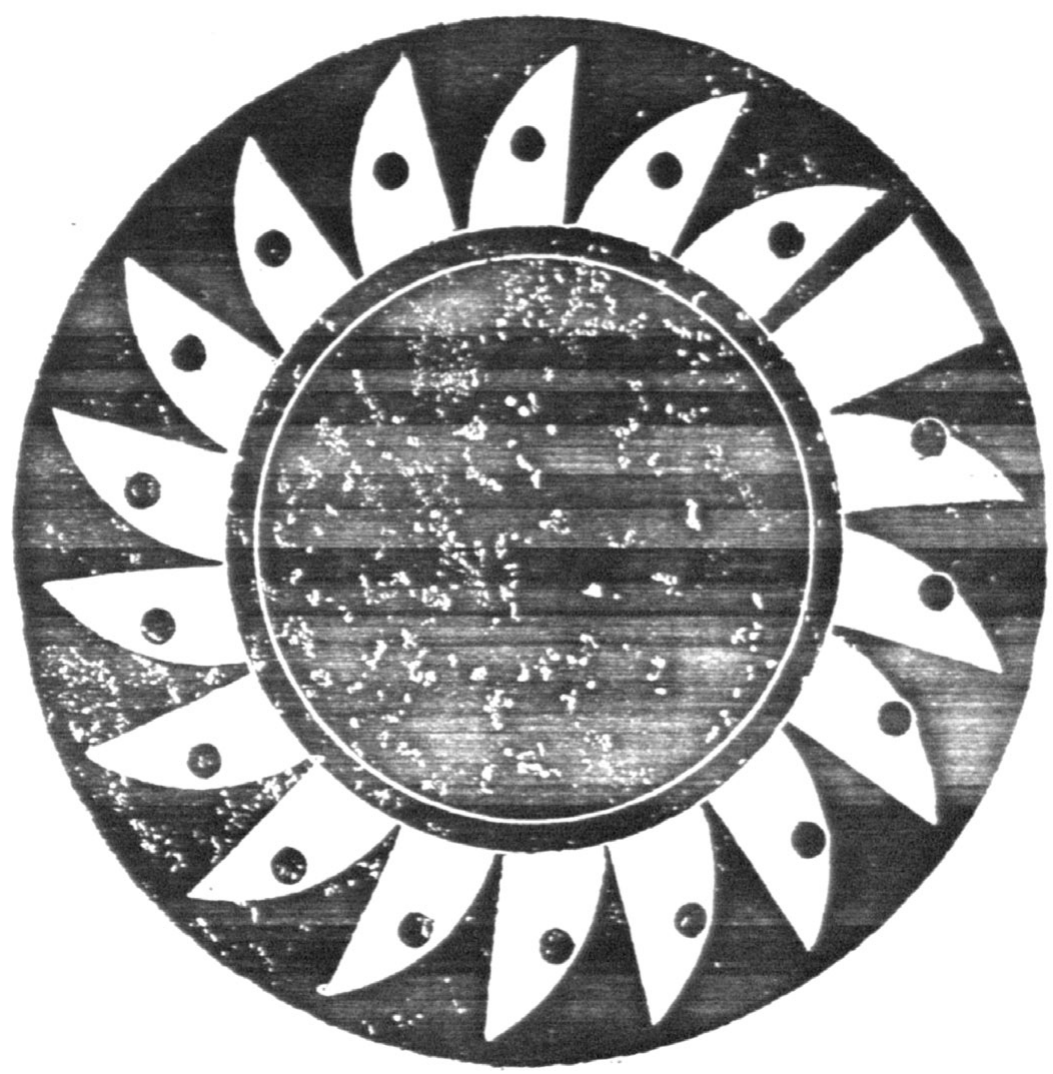

Fig. 5b. From Musée rétrospectif de la classe 12 photographie (matériel, procédés et produits) à l'exposition universelle internationale de 1900, à Paris. Rapport du comité d'installation. 1900 on p. 38.

satisfied with simply returning to drawings since these could only have "the degree of truthfulness that the drawer was able to give to them" (Marey 1894).

When Janssen first presented his photographic gun, he described the phenakistiscope as producing the effect of synthesis, and the revolver as producing its "inverse," analysis. Similarly, Marey, in the presentation of his photographic gun, underlined how its images could be used with a phenakistiscope (Marey 13 March 1882). These predictions proved premature. Both Janssen and Marey desired a photographic machine for both analysis and synthesis, one that would combine chronophotographic and phenakistiscopic technologies, but they could not find it.

\section{The dream falls apart}

From the middle of the nineteenth century to its end, a strong desire to achieve the effects of analysis and synthesis using photography motivated numerous scientists to 


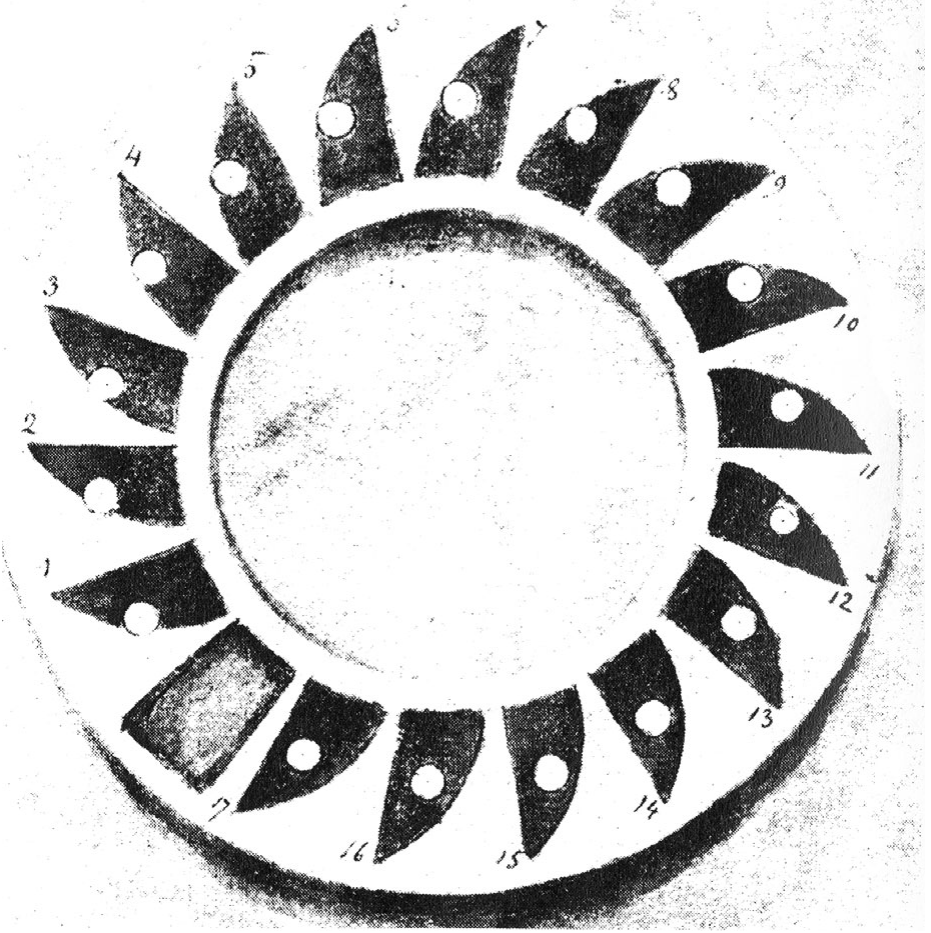

Fig. 5c. From Musée Marey, La passion du mouvement au XIXe siècle: hommage à E.J. Marey. Dijon: Fuchey, 1991, on p. 52.

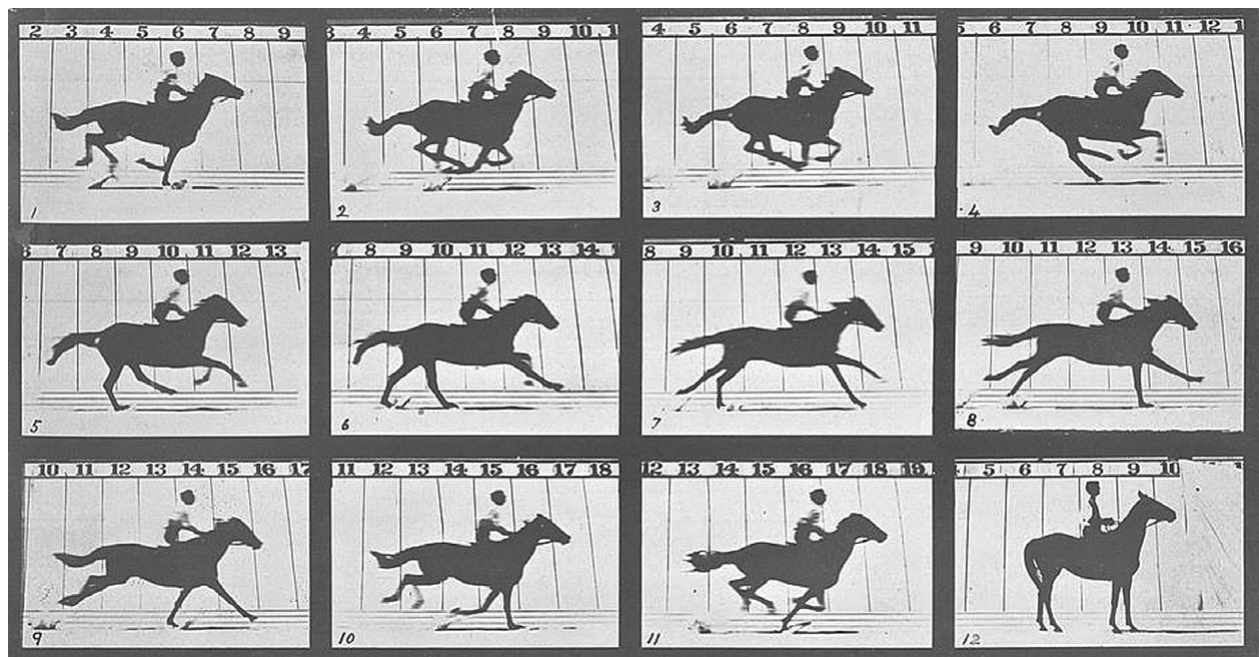

Fig. 6a. Photographs of the horse in gallop from Eadward Muybridge, The Horse in Motion (1878). 


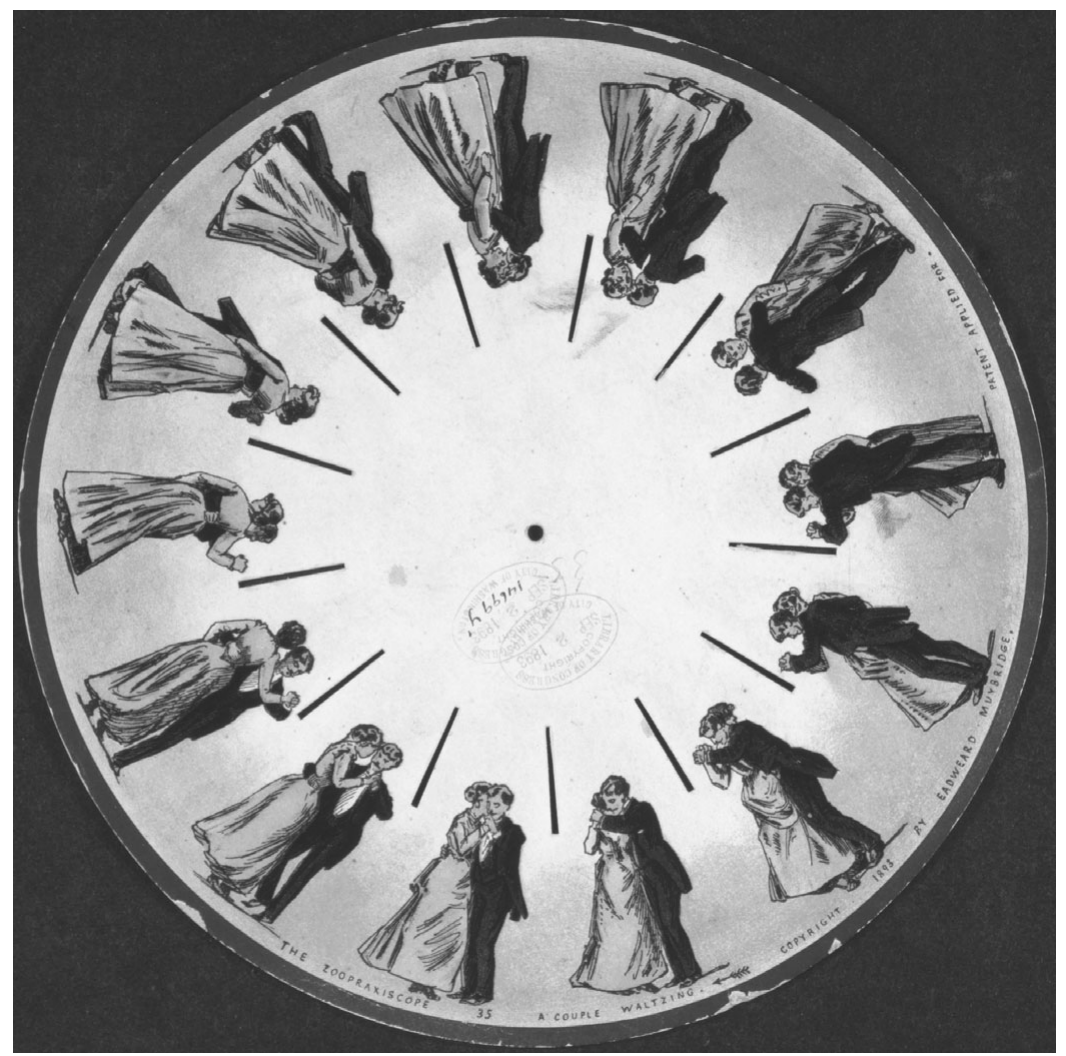

Fig. 6b. Drawings by Muybridge arranged on a phenakistiscope from 1893.

develop new technologies. Early cinematographic machines were frequently described in terms of the connection between the synthesis and analysis of movement: "All consist of a camera for obtaining the negative on a film, camera and mechanism which can serve to project the positive image" (Fabre n.d.; Trutat 1899a). Marey experimented with separate projection and recording components, but always tried to reintegrate them into a single, reversible machine. A book on the "photographic industry" remarked on the essential trademarks of Marey's machines: "In Marey's apparatus, as in the majority of similar instruments, the same instrument serves to produce the negative images and to project the positive one" (Fabre n.d.) Marey insisted on the benefits of having one apparatus perform two functions: "The chronophotograph does not need any modifications to become a projector" (cited in Gastine n.d.). At the turn of the century, Georges Demenÿ, the assistant of Marey who made important contributions to the technology, insisted that "so-called cinematographic apparatuses . . are nothing but reversible chronophotographs" (Demeny 1899). 


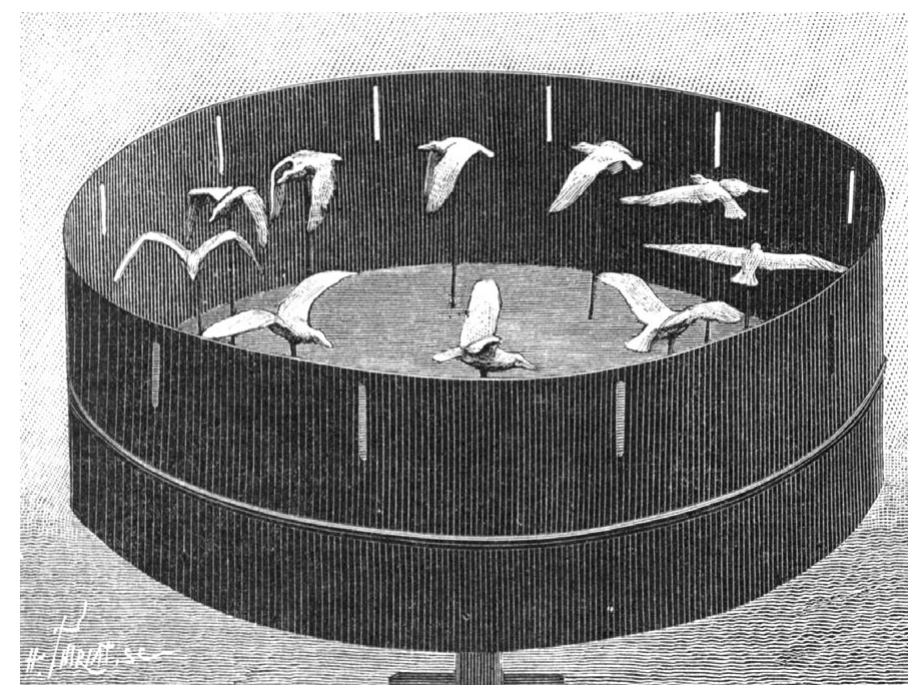

Fig. 7. Three-dimensional zoetrope with bird wax-figures by Marey from La Nature (1887), p. 12.

But the connection between analysis (shooting) and synthesis (projecting) largely lost its raison d'etre rapidly after it was achieved. In 1897 the Lumière brothers produced a cheaper camera designed only for projecting. Ten years later a writer to the popular Revue scientifique underlined the advantages of separating the recording and projecting functions of the apparatus: "industrial practices have shown that instead of inverting the chronophotograph, it is preferable to separate the instruments from each other. That is to say, to construct special apparati for photographic recording" (Banet-Rivet 1 August 1907). These changes had important consequences. Having two apparati, instead of one, widened the gap between spectators and producers. The development of mass media and consumer culture further increased the ratio between producers and consumers, where the latter became both gendered and orientalized. Another change involved increasingly hiding the machine's internal mechanisms. While most scientists strove to make the mechanisms regulating synthesis and analysis as visible and evident as possible, the cinematographic industry was concerned with exactly the opposite in order to enhance the medium's phantasmagoric effect. ${ }^{2}$

When "industrial practices" revealed the advantages of separating the machines for recording from those for projecting, some scientists felt that their efforts to establish a cinematographic connection between synthesis and analysis had been subverted. They saw their solution fall apart just a few years after their decades-long search came to

\footnotetext{
${ }^{2}$ For the connection between illusion, phantasmagoria, and "the occultation of production by means of the outward appearance of the product," see Adorno [1952] 1981, and its discussion in Crary 1999. For the concern of scientists with making the magic lantern's mechanism visible, see Secord 2002.
} 
an end. Many scientists, including Marey, resisted these changes. They explained to the public what they considered to be the essence of cinematography and stressed their role in its invention. While many scientists, including numerous astronomers, dedicated a great part of their lives to "inverting the chronophotograph," once this inversion was completed, the public found no need for it. ${ }^{3}$ Scientists, including Janssen and Marey, who had made so much progress with chronophotography, suddenly left the development of cinematography to others and frequently opposed further improvements to the medium. ${ }^{4}$

Editing became common. Movies fascinated and entertained. Other changes followed, such as introducing sound. Cinematographic technologies moved out of laboratories and into places of spectacle. Marey lamented the changes in this direction. By 1899 he had become painfully aware that the reason why photography "has gained popularity, is not due to its true worth (valeur veritable): she has gained this good fortune by interesting the public with the charming illusions which she gives" The physiologist did not believe the public's fascination could be sustained: "No matter how perfect is the reproduction of familiar scenes, we start growing tired of watching them. The animation of a street with passers-by, the horses, the vehicles which cross each other in diverse senses do not suffice anymore to capture attention." Even if new tricks were found, he believed they would eventually tire the public: "Already the search of curious subjects is imposed. One demands of faraway places new spectacles, which, soon, will not be sufficient in themselves for sustaining interest" (Marey 1899). He was wrong.

Marey distanced himself from these spectacular trends. In numerous publications, he described cinema's faults and chronophotography's merits by differentiating chronophotography from the vulgar vision-based spectacles of cinema: "Chronophotography must, then, renounce the representation of phenomena as we see it" (ibid.). ${ }^{5}$ In his Traité de Chronographie (1899) describing Lumière's methods, he was characteristically deprecatory: "Furthermore, the absolute perfection of projections which naturally provoke the public's enthusiasm, is not that which, personally, concerns

\footnotetext{
${ }^{3}$ Historians have similarly forgotten about the difficulties that characterized research from the time of Janssen's revolver to the Lumière camera. Frederich Kittler, for example, claims that: "One only would have had to follow the principles of the revolver and supplement a rotating photo storage device with a rotating photo projector" (Kittler 1999).

4 The historian of photography Joel Snyder described Marey's apparently paradoxical position as a "wobble" (Snyder 1998).

${ }^{5}$ The complete statement is: "but in the end that which [animated photography] shows, the eye can see directly. They add nothing to the power of our eyes, they do not remove any of their illusions. And yet, the true character of the scientific method is to supplement the insufficiency of our senses or to correct their errors. To achieve that, chronophotography must, then, renounce the representation of phenomena as we see it." He expressed this same idea again to his fellow physiologists: "But the true utility of the phenakistiscope is not to give us the same sensation which our eyes perceive in the face of moving objects, it should show us that which our eyes cannot perceive through direct observation, that is to say, it should detail all the phases of an act which seems confused due to the persistence of retinal impressions" (Marey 1889).
} 
me the most." One year later, for the 1900 Universal Exhibition in Paris, he continued to insist: "Animated projections, interesting as they are, are of little advantage to science, for they only show what we see better with our own eyes" (Marey 1902). They were only interesting, according to him, when they were precisely timed or significantly slowed down or accelerated.

For non-scientists the essence of cinema was increasingly defined in terms of its emancipation from the laboratory - a step which occurred along with the adoption and mass production of filmstrips (Banet-Rivet, 1 August 1907; Trutat 1899b). The development of the cinematographic industry was part of a modern trend that extended laboratory methods to the outside world through new industrialized and standardized production methods. Eugène Trutat, honorary president of the Societé photographique and director of the Muséum d'Histoire naturelle at Toulouse, noticed how "from the laboratory of men of science the modern discovery goes to the factory" (Trutat 1899a). ${ }^{6}$ This process was often welcomed and driven by scientists, who saw in it a way of expanding laboratory knowledge into the outside world through standardized largescale networks (Schaffer 1992). But in the case of cinematography, the move to the factory produced an additional, unexpected effect. Instead of extending the networks of science outwards, industrialization fostered a fictional space that was increasingly considered separate from science. ${ }^{7}$ This space was sustained by the separation of recording from projecting, and thrived in the growing gap between producers and consumers.

Even when it was undeniable that the "true worth" of cinema as conceived by him was not fully appreciated, Marey still believed the allure of spectacle would one day end. Chronophotography and its "inverse" would return to the privacy of the laboratory: "It is then that Chronophotography, returning to its origins, will become scientific once again. She will become the popularizer of these always novel spectacles, always captivating, which savants still enjoy alone in their laboratories" (Marey 1899). Although a number of scientists continued to use film in laboratory settings, cinematography never returned completely to the laboratory.

Scientists' celebration of the solution to a decades-long problem was surprisingly short-lived. Astronomers quickly encountered new problems with cinematography. The separate shooting and projecting instruments worked at slightly different speeds, rendering commercial cinematography largely useless for exact studies. For recording the solar eclipse of April 17, 1912, and the lunar eclipse on March 12, 1914, the few remaining astronomers who wanted to film the event were forced to introduce a number of changes to the technology, including a clock and filming it next to the

\footnotetext{
${ }^{6}$ For the relationship of the artistic studio, the laboratory, and the factory, see Obrist and Vanderlinden 2001, and especially Galison and Jones 2001.

${ }^{7}$ Actor-network-theory (ANT), where the expansion of scientific networks make them incrementally stronger and more pervasive, cannot account for these effects. They are, in contrast, best described in Jean-Francois Lyotard's later work (see Lyotard 1999).
} 
celestial phenomena. Filming an astronomical event "did not - as it was sometimes claimed - consist of placing a cinematographic camera" at the ocular of a telescope (Vlès c.1914). Most astronomers simply abandoned the medium. Even Faye, who earlier had been enthusiastic about photography's ability to replace the observer, eventually changed his expectations. For precisely noting the motion of transit stars, he advocated the use of an "impersonal" micrometer. ${ }^{8}$

In physiology, the medium underwent a similar transformation. In 1911, the Institut Marey considered its future as a "center of cinematography applied to physiology." But it was hampered by "chronophotography's only inconvenience of being very expensive." The film production company Pathé offered to furnish it with "a considerable number of meters of film," in exchange for the monopoly to exploit their films. After "an important discussion" this proposition "was not accepted, because of the danger that the Institut could suffer by the public projection of certain sensational experiments." 9 The rejection of Pathé's generous offer signaled an important change from early cinematographic research which was simultaneously at the cutting-edge of both science and spectacle.

By the middle of the twentieth century, the distance between scientists and cinematographers had widened to the point that Bazin chastised the preeminent historian of cinema Georges Sadoul, who briefly mentioned Janssen in his famous Histoire du cinéma mondial des origines à nos jours, for tracing the origins of cinema to science (Sadoul 1972).

\section{An impossible dream: Bergson's critique}

Cinematography undoubtedly continued to be used in many sciences, ranging from cell biology, medicine, to physics. Some famous examples focus on Lucien Bull, a student of Marey, who used a high-speed camera to analyze rapid events ranging from bullets penetrating plywood to the rapidly beating wings of dragonflies; Charles Henri turned to it for analyzing Brownian motion; Jean Comandon used microcinematography to study living cells; and Dr. Eugène Doyen employed it for documenting medical surgeries, including a famous case of separating twins in 1897. However, it never fulfilled some of the desires that motivated early researchers. It did not reveal all of world history, nor did it eliminate the observer, as Faye had wanted. Its representation

\footnotetext{
${ }^{8}$ By the first decades of the twentieth century astronomers placed their hopes on non-cinematographic instruments for recording transits. In 1910 an "impersonal micrometer" was adopted in the Paris Observatory for observing stars moving across the sky. With a "traveling wire" that bisected the image of a star, it recorded its movement automatically. Faye placing his trust on the new micrometer: "The only resort, in order not to be arrested at the actual level of precision, is to eliminate the observer as has been more or less successfully accomplished using the impersonal micrometer" (Faye 1883). A previous edition of Faye's remarks did not yet include the "impersonal micrometer." He curtly wrote: "The only resort, in order not to be arrested at the actual level of precision, is to eliminate the observer" (Faye 1881).

${ }^{9}$ Notebook, Procès verbaux des reunions, Marey Box CXII, Collège de France.
} 
of movement was of a limited, special kind, and it did not solve the riddle of relating analysis to synthesis. Critics claimed that chronophotography did not reveal all the constitutive elements of movement, as Janssen and Marey had dreamed it would do. It never entirely captured fleeting moving phenomena - something escaped.

The philosopher Henri Bergson articulated these deficiencies in detail. His point was simple. The cinematographic camera captured an illusory form of movement; it did not capture real movement. Why? Because "film could pass ten times, one hundred times, one thousand times faster" and "that which passes would not be modified" (Bergson [1934] 1991). Most things changed, and while Bergson agreed that part of the universe could be studied in this way - most of it could not. What the cinematographic method inevitably missed was the "perpetual creation of possibility" that was, according to Bergson, the undeniable mark of the living world (ibid.). When directly compared to how it appeared on the screen, the world seemed more alive than ever; its future ever more mysterious.

Bergson's earliest criticisms of the cinematographic method arose in the context of astronomy - precisely where these machines were first used and most desired. Janssen had built his photographic revolver to study the transit of Venus, and almost two decades afterwards, Bergson became engaged in a discussion about how precise the timing of these kinds of events could actually be. A common view held that "An eclipse, or even better, the transit of Venus across the sun, is an interesting and instructive fact because it is very precise." But Bergson offered a different perspective. This moment was set apart from the rest of moving reality by the scientist: "It is the astronomer that catches the position of the planet from the continuous curve it traverses" (Bergson [1901] 1972). ${ }^{10}$ The apparent precision in timing this event was simply a construct.

Rudimentary pre-cinematographic cameras first used during the transit of Venus were greatly improved in the years that followed. In light of these improvements Bergson's critique grew even bolder and sharper. In Creative Evolution, he expanded his early ideas further. It was not only Venus's form - even under the scrutiny of Janssen's revolver - that was elusive, but all forms: "there is no form, since form is immobile and reality is movement. What is real is the continual change of form: form is only a snapshot view of transition" (Bergson 1998; emphasis added). This perspective stood in contrast to the one described in the 1830s by the Belgian scientist Joseph Plateau who developed popular phenakistiscopic instruments. Plateau argued that these instruments rescued form from the movement which obscured it: "One could in that way . . obtain the real form of objects whose speed prevents us from distinguishing" (cited in Olivier 1882; emphasis added). Yet for Bergson, the relation was simply the reverse: forms derived from movement (Canales 2006).

The central point was that no scientific instrument - no matter how perfect could entirely capture movement. Bergson found the "cinematographic method"

10 “C'est l'astronome qui cueille cette position de l'astre sur la continuité de la courbe qu'il décrit." 
both pervasive and constraining - common and scientific knowledge were completely restricted by it. Referring not merely to the modern cinematographic camera, but to the proclivity of the human mind for arranging temporal images spatially, he criticized its restrictiveness, and urged scientists to "set the cinematographical method aside" and search instead for a "second kind of knowledge" (Bergson 1998).

On numerous occasions Bergson explained how cinematography provided viewers with an illusory kind of movement that differed from real movement: "Suppose we wish to portray on a screen a living picture ... how could it, at its best, reproduce the suppleness and variety of life?" By taking "a series of snapshots" and projecting "these instantaneous views on the screen, so that they replace each other very rapidly," movement could be reproduced. Yet this illusory movement resulted from shifting real movement elsewhere. In the case of cinema, it resulted from shifting it inside the apparatus: "In order that the pictures may be animated, there must be movement somewhere. The movement does indeed exist here; it is in the apparatus" (Bergson 1998). Bergson exhorted his followers to look away from the screen and peer instead into cinematographic black boxes to find real movement hidden there; to find, inside, a moving universe which could never be divided into separate, constitutive elements.

\section{Who made the dream come true?}

Sometimes people - especially scientists - get what they want. Many scientists made essential contributions to cinematographic technologies. But, like almost all inventions, considerable debate surrounded its origin. Who invented it? Many technologies built before 1895 already fulfilled some essential components of cinema. Projection technologies had a long history, usually traced back to the eighteenth century and to magic-lantern technologies. By the time that cinematography appeared, these magiclantern shows had been perfected to such a degree that they attracted thousands of spectators on a weekly basis (Crary 1998). Although these movement projection technologies were based on drawings, considerable progress had been achieved with photographs. Thomas Edison's Kinetoscope was already commercially available, although it was based on a limited number of images designed for single viewers.

An important change came with the Lumière cinematographic camera. This machine, after all, embodied some of the most essential characteristics that would characterize the medium for years to come. It used photographs arranged in strips and it also projected the images on the screen, allowing many to partake in the spectacle. These two characteristics, however, were not enough to convince everyone that the parentage of cinematography belonged exclusively to the Lumière brothers.

Like the telescope and photography, cinema can be said to be an invention without an inventor. But it was, additionally, an invention that undermined the categories of invention and inventor themselves. 
In the 1920s a full-blown battle over the invention of cinematography was waged. Many candidates vied for the honor. ${ }^{11}$ Marey appeared as one of the top candidates, followed by the astronomer Janssen. Marey himself saw his chronophotographic work as an improvement of Janssen's, generously acknowledging that "it is thus to him [Janssen] who belongs the honor" of having inaugurated chronophotographic methods and stressing that his own changes were of degree and never in kind (Marey 1894). Janssen himself placed his chronophotographic revolver at the origin of the invention of cinematography. On June 12, 1895, he witnessed one of the first presentations of the Lumière camera at the Congrès de l'Union nationale des Sociétés photographiques and saw himself majestically projected unto a screen. The brothers had filmed him while casually disembarking his boat to attend the event and later captured him conversing with a friend. ${ }^{12}$ At the end of the day, Janssen was scheduled to give the closing speech. He eloquently gave to the Lumière's the honor of having taken a "considerable step" in "animated photography." But he "distinguished" what they had done - and what he had seen that day - from his "analytical photography" (Janssen 1895, cited in Coissac 1925).

Some supporters claimed that the "essence" of cinema resided already in the previous invention of chronophotography: "the cinematograph is nothing else than reversed chronophotography." For this reason, the list of inventors was often expanded to include some of the first scientists to work with sequential photographs (Mair 1905, cited in Coissac 1925). ${ }^{13}$ But those who, like Marey and Janssen, focused on cinema's chronophotographic origins were soon left in the minority. ${ }^{14}$ Most people started finding the roots of cinematography in ancient technologies for entertainment and spectacle, not in science. A writer in the Revue scientifique traced cinema's origins to Chinese shadow puppets, tingeing spectatorship practices with a strong dose of orientalism: "The yellow people, because of the special mentality which leads them - their writing is a proof of this - to the representation of the external world by image ... are fascinated by the shadows. The Turcs and Arabs, them too, are equally fond of this spectacle" (Banet-Rivet, 1 August 1907). He explained how "crowds (the foule) ... admire everything and always ... and this continuous ever-increasing admiration ... can alone explain the birth and considerable development, since 1895, of the cinematography industry" (ibid.). ${ }^{15}$ For him, as for most writers who followed, the essence of cinema coincided with the adoption of filmstrips and with the separation of projecting and recording - two changes that allowed it to come out of the laboratory.

\footnotetext{
11 This debate is followed in detail in Coissac 1925 and in Braun 1992; in both volumes it is undertaken in the spirit of setting the historical record straight.

${ }^{12}$ The films are Promenade des congressistes sur les bords de la Saône and M. Janssen discutant avec son ami Lagrange.

${ }^{13}$ Francis Mair was a pseudonym of Ed. Benoît-Levy.

14 The physiologist Charles Richet stubbornly defended Marey as inventor, and did not mention Janssen. For him "the essential condition is the production, on a strip, of a series of reversible images: cinematography is nothing but that" (Richet 1924, cited in Coissac 1925).

${ }^{15} \mathrm{He}$ included the caveat that "all people, all races" loved cinema (Banet-Rivet, 1 August 1907).
} 
Thus, the philosopher Gilles Deleuze considered that an essential part of "cinema's position at the outset" was that "the apparatus for shooting [appareil de prise de vue] was combined with the apparatus for projection, endowed with a uniform abstract time." Finding this original condition limiting, Deleuze focused on cinema only after it surpassed its humble origin, studying instead the "emancipation of the point of view, which became separate from projection" (Deleuze 1986). But this transformation was not simply a technical improvement, especially not if considered in terms of what many early cinematographic researchers desired.

As machines that were once conceived for connecting synthesis with analysis were transformed and used for the purpose of cinema, a new conception of what was considered the essence of cinematography and who were its inventors started to gain prominence. This conception stood in stark opposition to the conception that cinematography's association with chronophotography was essential.

Diverse interests played important roles in debates about the origin of cinematography. Scientists, such as Marey, competed against industrialists for the honor; Frenchmen against Americans; and underlings fought hard against their superiors. Scientists, including Marey, nonetheless seemed to lose the fight. In the postwar period the film critic André Bazin downplayed their role to the extent that he confidently stated that "the cinema owes virtually nothing to the scientific spirit" and that Marey "was only interested in analyzing movement and not in reconstructing it" (Bazin [1946] 2005).

Debate was so rampant that the first history of cinema written by an academic professor, Hugo Münsterberg, was led to the conclusion of just how "arbitrary" the notion of invention really was:

It is arbitrary to say where the development of the moving pictures began and it is impossible to foresee where it will lead. What invention marked the beginning? Was it the first device to introduce movement into the pictures on a screen? Or did the development begin with the first photographing of various phases of moving objects? Or did it start with the first presentation of successive pictures at such a speed that the impression of movement resulted? Or was the birthday of the new art when the experimenters for the first time succeeded in projecting such rapidly passing pictures on a wall? (Münsterberg 1916)

By the post-WWII period, the historian of technology Siegfried Giedion further complicated the very concept of "scientific invention" and its relation to technological change. For him, the chronophotographic work of Janssen and Marey was a salient moment at the origin of the "anonymous history" of our twentieth-century technologically-driven modernity. Giedion considered Marey's work the immediate and necessary precedent for mechanization to "take command" in the twentieth century - when the importance of "the physiologist" shifted to that of "the production engineer" (Giedion 1948). 
More recently, the media historian Friedrich Kittler claimed that "Münsterberg's questions remain unanswered," seeing in the original query about the invention of cinematography the reason why later researchers, such as Michel Foucault, altogether abandoned the search for individual actors to account for historical change and why they opted instead for an intrapersonal "discourse analysis" (Kittler 1999). Since then, posthumanist studies have completely abandoned the task of searching for the individual actors of historical change.

\section{Philosophy, between dreams and laughter}

A history of cinematographic desires provides a different view of the technology's origin, and its relation to science. In the first decades of the twentieth century, it was common to lament how previous writers - even those who came from an "academic milieu" - often "confused chronophotography ... and cinematography" (Coissac 1925). Raoul Grimoin-Sanson, who worked with Marey and contributed to a variety of inventions, expressed this common complaint succinctly, urging "all persons of good faith not to confuse chronophotography and cinematography, analytical photography and animated photography, analysis and synthesis" (Grimoin-Sanson August 1923, cited in Coissac 1925). Those concerned with setting the record straight about the invention chastised authors who "confused chronophotography and cinematography with the same oversight of confusing coming and going" (Coissac 1925). Something that was as evidently different as "coming and going" for these twentieth-century authors seemed to have been mixed up in the previous century.

What these twentieth-century authors considered an unfortunate confusion had once been a long sought-after connection. Janssen's desire to capture movement was such that, instead of furthering the rift between the past, present, and future, aimed to connect them even more intimately. "One day, perhaps, the past, present and future shall no longer exist for the astronomer," he dreamed (Janssen 1883). But decades later one of the Lumières first films, Charcuterie mécanique (1895), showed just how absurd and even comical this dream was. After recording the successive steps of a pig being butchered and made into sausage, they played it backwards: from the sausage came out a pig and from the audience - laughter. In the 1960s, the famous physicist Richard Feynman explained how thermodynamics was frequently demonstrated in the classroom by playing a movie backwards: "The demonstration of this in lectures is usually made by having a section of moving picture in which you take a number of phenomena, and run the film backwards, and then wait for all the laughter. The laughter just means this would not happen in the real world." Feynman dealt with the burst of "laughter" by bringing an injunction against it: "The moving picture should work the same going both ways, and the physicist who looks at it should not laugh" (Feynman 1965).

The cinematographic machine appeared along with a new comic situation and a new task for philosophy. The philosopher Raymond Ruyer, who set out to watch and 
analyze films in reverse, found through careful research a new task for philosophy, that of "analyzing the logical residue that the progress of science leaves behind" (Ruyer 1936).

But Janssen's dream was neither a simple confusion or simply comical: the way of understanding these technologies was, in fact, directly connected to contemporaneous views of the present, past, future and how they related to each other.

In a tragic sense, early researchers produced exactly the opposite of what they desired. Bazin explained how scientists had wanted to possess a machine that would give them the "recreation of the world in its own image." Yet, ironically, cinematography proved to them the sheer impossibility of ever obtaining an "image unburdened from the freedom of interpretation" (Bazin [1946] 2005). And although they had tried to use it to connect analysis and synthesis, the machine made more patent than ever the irreversibility of time so potently underlined by Bergson. If it is often said that the cinematographic camera put "life on the screen," a history of cinematographic desires reveals how it also put a screen on life.

\section{References}

Adorno, Theodor. [1952] 1981. In Search of Wagner. Translated by Rodney Livingstone. London: NLB. Andriopoulos, Stefan. 2005. "Psychic Television." Critical Inquiry 31:618-637.

Banet-Rivet, Pierre. 1907. "La Représentation du mouvement et de la vie." Revue des deux mondes 40:590-621.

Bazin, André. [1946] 2005. "The Myth of Total Cinema.” In What is Cinema? Translated by Hugh Gray, 17-22. Berkeley: University of California Press.

Bergson, Henri. [1901] 1972. "Le parallélisme psycho-physique et la métaphysique positive." In Mélanges, 463-502. Paris: Presses Universitaires de France.

Bergson, Henri. [1922] 1972. "Durée et simultanéité: a propos de la théorie d'Einstein." In Mélanges, 58-244. Paris: Presses Universitaires de France.

Bergson, Henri. [1934] 1991. "La Pensée et le mouvant." In Oeuvres, 1251-1482. Paris: Presses Universitaires de France.

Bergson, Henri. 1998. Creative Evolution. Mineola NY: Dover.

Bernstein, Aaron. 1873-1874. Naturwissenschaftliche Volksbücher. Berlin: Dümmler.

Biagioli, Mario. 2006. Galileo's Instruments of Credit: Telescopes, Images, Secrecy. Chicago: University of Chicago Press.

Biagioli, Mario and Peter, Galison, eds. 2003. Scientific Authorship: Credit and Intellectual Property in Science. New York: Routledge.

Braun, Marta. 1992. Picturing Time: The Work of Etienne-Jules Marey (1830-1904). Chicago: University of Chicago Press.

Canales, Jimena. 2006. "Movement before Cinematography: The High-Speed Qualities of Sentiment." Journal of Visual Culture 5(3):275-294.

Clausberg, Karl. 2008. "A Microscope for Time: What Benjamin and Klages, Einstein and the Movies Owe to Distant Stars." In Given World and Time, edited by Tyrus Miller, 297-358. Budapest: Central European University Press.

Coissac, Michel G. 1925. Histoire du cinématographe. Paris: Éditions du "Cinéopse."

Crary, Jonathan. 1998. "Attention and Modernity in the Nineteenth Century." In Picturing Science, Producing Art, edited by Caroline A. Jones and Peter Galison, 475-499. New York: Routledge. 
Crary, Jonathan. 1999. Suspensions of Perception: Attention, Spectacle, and Modern Culture. Cambridge MA: MIT Press.

Cuyer, Edouard. 1883. Allures du cheval démontrées a l'aide d'une planche coloriée, découpée, superposée et articulée. Paris: J.-B. Baillière et fils.

Deleuze, Gilles. 1986. Cinema 1: The Movement-Image. Minneapolis: University of Minnesota Press.

Deleuze, Gilles and Félix, Guattari. 1972. L'Anti-Oedipe. Paris: Les Editions de Minuit.

Demeny, Gilles. 1899. “Études sur les appareils chronophotographiques.” L'année psychologique 5:347-368.

Eberty, Felix George Friedrich. [1846] 1882. The Stars and the Earth; or, Thoughts upon Space, Time and Eternity. Boston: Lee and Shepard Publishers.

Einstein, Albert. [1949] 1991. “Autobiographical Notes.” In Albert Einstein: Philosopher-Scientist, edited by Paul Arthur Schilpp, 2-94. La Salle IL: Open Court.

Fabre, Charles. n.d. Les industries photographiques. Paris: Gauthier-Villars.

Faye, Hervé. 1849. "Sur les observations du soleil." Comptes rendus des séances de l'Académie des Sciences 28;241-244.

Faye, Hervé. 1854. "Sur la différence de longitude entre Paris et Londres. Discours de réception." In Mémoires de l'Académie de Stanislas, v-xviii.

Faye, Hervé. 1858. "Sur le photographies de l'éclipse du 15 mars, présentées par MM. Porro et Quinet," Comptes rendus des séances de l'Académie des Sciences 46:705-710.

Faye, Hervé, 31 October 1861, Preußische Staatsbibliothek zu Berlin, Sammlung Darmstädter I 1846(6) Faye, 3.

Faye, Hervé. 1863. "Réponse à une inculpation de M. Le Verrier relativement à la part que M. Faye a prise à la détermination de la différence de longitude entre Londres et Paris." Comptes rendus des séances de l'Académie des Sciences 56:154-158.

Faye, Hervé. 1864. "Sur les erreurs d'origine physiologique." Comptes rendus des séances de l'Académie des Sciences 59:473-480.

Faye, Hervé. 1881. Cours d'astronomie de l'École polytechnique. Paris: Gauthier-Villars.

Faye, Hervé. 1883. Cours d'astronomie et de géodésie de l'École polytechnique. Paris: Gauthier-Villars.

Feynman, Richard Phillips. 1965. The Character of Physical Law. London: BBC.

Flammarion, Camille. 1873. Stories of Infinity: Lumen; History of a Comet; In Infinity. Boston: Roberts Brothers.

Galison, Peter and Caroline A. Jones. 2001. "Trajectories of Production: Laboratories, Factories, Studios." Laboratorium, edited by Hans Ulrich Obrist and Barbara Vanderlinden, 205-210. Cologne: Dumont.

Gastine, Louis. n.d. "Nouvelles modifications du chronophotographe par M. E. J. Marey." In La chronophotographie. Paris: Gauthier-Villars.

Giedion, Siegfried. 1948. Mechanization Takes Command: A Contribution to Anonymous History. New York: Oxford University Press.

Grimoin-Sanson, Raoul. 1923. Cinéopse 48 (August).

Janssen, Jules. 1876. "Bulletin des sociétés savantes, Académie des sciences de Paris.- 2 Octobre 1876: Observations sur les passages devant le soleil de corps intra-mercuriels." Revue scientifique 18(14 October):383.

Janssen, Jules. 1883. "Les progrès de la astronomie physique." L'Astronomie: Revue mensuelle d'astronomie populaire, de météorologie et de physique du globe 2(4):121-128.

Janssen, Jules. 1888a. "La photographie céleste.” Revue scientifique 33(14 January).

Janssen, Jules. 1888b. La Photographie céleste, conférence faite au Congrès de Toulouse. Paris: Administration de deux revues.

Kirk, Geoffrey Stephen and John Earle Raven. 1957. The Presocratic Philosophers: A Critical History with a Selection of Texts. Cambridge UK: Cambridge University Press.

Kittler, Friedrich. 1990. Discourse Networks 1800/1900. Stanford: Stanford University Press.

Kittler, Friedrich. 1999. Gramophone, Film, Typewriter. Stanford: Stanford University Press.

Kittler, Friedrich A. 2010. Optical Media: Berlin Lectures 1999. Cambridge UK: Polity. 
Koselleck, Reinhart Urbain. 2004. Futures Past: On the Semantics of Historical Time. New York: Columbia University Press.

Le Verrier, Urbain. 1876. "Bulletin des sociétés savantes, Académie des sciences de Paris.- 2 Octobre 1876: Les planètes intra-mercurielles." Revue scientifique 18 (14 October):383.

Lee, H. D. P. 1936. Zeno of Elea: A Text. Cambridge UK: Cambridge University Press.

Lyotard, Jean-François. 1999. "A Postmodern Fable." In Postmodern Fables, by Jean-François Lyotard, 83-102. Minneapolis: University of Minnesota Press.

Mair, Francis. 1905. "Débuts du cinématographe." Phono-Ciné-Gazette.

Marey, Etienne-Jules. 1882. "Sur la reproduction, par la photographie, des diverses phases du vol des oiseaux." Comptes rendus des séances de l'Académie des Sciences 94(13 March):683-684.

Marey, Etienne-Jules. 1888. "Modifications de la Photo-chronographie pour l'analyse des movements exécutés sur place par un animal." Comptes rendus de l'Académie des sciences 107:607-609.

Marey, Etienne-Jules. 1889. "La photochronographie et ses applications à l'analyse des phénomènes physiologiques." Archives de physiologie normale et pathologique, publiées par MM. Brown-Séquard, Charcot, Vulpian 1:508-612.

Marey, Etienne-Jules. 1894. Le Mouvement. Paris: G. Masson.

Marey, Étienne-Jules. 1899. Préface. La photographie animée. Paris: Gauthiers-Villars.

Marey, Etienne-Jules. 1902. "The History of Chronophotography." Annual Report of the Board of Regents of the Smithsonian Institution, showing the operations, expenditures, and condition of the Institution for the year ending June 30, 1901, 317-340.

Münsterberg, Hugo. 1916. Photoplay. New York: Appleton.

Obrist, Hans Ulrich and Barbara Vanderlinden, eds. 2001. Laboratorium. Cologne: Dumont.

Olivier, Louis. 1882. "Physiologie: La photographie du mouvement." Revue scientifique 30:802-811.

Pang, Alex Soojung-Kim. 1997. "'Stars Should Henceforth Register Themselves': Astrophotography at the Early Lick Observatory." British Journal for the History of Science 30:177-202.

Pohle, Joseph. 1885. Die Sternwelten und ihre Bewohner. Eine wissenschaftliche Studie über die Bewohnbarkeit und die Belebtheit der Himmelskörper nach dem neuesten Standpunkte der Wissenschaften. Cologne: Bachem.

Popper, Karl R. and William Warren Bartley. 1982. The Open Universe: An Argument for Indeterminism. Totowa NJ: Rowman and Littlefield.

Ruyer, Raymond. 1936. "Le Sens du temps. Réflexions sur des films renversés." Recherches philosophiques $52-64$.

Sadoul, Georges. 1972. Histoire du cinéma mondial. Des origines à nos jours. Paris: Flammarion.

Schaffer, Simon. 1992. "Late Victorian Metrology and Its Instrumentation: A Manufactory of Ohms." In Invisible Connections, Instruments, Institutions and Science, edited by Robert Bud and Susan Cozzens, 23-56. Bellingham: SPIE Optical Engineering Press.

Secord, Anne. 2002. "Botany on a Plate: Pleasure and the Power of Pictures in Promoting Early Nineteenth-Century Scientific Knowledge." Isis 93:28-57.

Simondon, Gilbert. 1958. Du mode d'existence des objets techniques. Paris: Aubier-Montaigne.

Snyder, Joel. 1998. "Visualization and Visibility." In Picturing Science, Producing Art, edited by Caroline A. Jones and Peter Galison, 379-397. New York: Routledge.

Thibault, Ghislain. 2010. "Éthéréalisation: amorces d'une contre-histoire." Ph.D. diss., Département de communication, Université de Montréal, Canada.

Thomson, William. 1874. "Kinetic Theory of the Dissipation of Energy." Nature 441-444.

Tiphaigne de la Roche, Charles-François. 1760. Giphantie. A Babylone (Paris: Nicolas-François Moreau).

Trutat, Eugène. 1899a. Dix leçons de photographie. Cours professé au Muséum de Toulouse. Paris: GauthierVillars.

Trutat, Eugène. 1899b. La photographie animée. Paris: Gauthiers-Villars.

Vitoux, Georges. 1896. La Photographie du mouvement. Paris: Chamuel.

Vlès, Fred. c.1914. La Cinématographie Astronomique. Paris: Charles Mendel. 